\title{
Mesothelin/CD3 half-life extended bispecific T-cell engager molecule shows specific tumor uptake and distributes to mesothelin and CD3 expressing tissues
}

Frans V. Suurs ${ }^{1}$, Grit Lorenczewski², Julie M. Bailis ${ }^{3,}$ Sabine Stienen², Matthias Friedrich ${ }^{2}$, Fei Lee ${ }^{3}$, Bert van der Vegt ${ }^{4}$, Elisabeth G.E. de Vries ${ }^{1}$, Derk Jan A. de Groot ${ }^{1}$ and Marjolijn N. Lub-de Hooge ${ }^{5,6}$.

${ }^{1}$ Department of Medical Oncology, University Medical Center Groningen, Groningen, the Netherlands; ${ }^{2}$ Amgen Research Munich GmbH, Munich, Germany; ${ }^{3}$ Amgen Inc., South San Francisco, CA, USA; ${ }^{4}$ Department of Pathology, University Medical Center Groningen, Groningen, The Netherlands; ${ }^{5}$ Department of Clinical Pharmacy and Pharmacology, University Medical Center Groningen, Groningen, the Netherlands; ${ }^{6}$ Department of Nuclear Medicine and Molecular Imaging, University Medical Center Groningen, Groningen, the Netherlands

\section{Corresponding author:}

M.N. Lub-de Hooge, PharmD, PhD, Department of Clinical Pharmacy and Pharmacology, University Medical Center Groningen, University of Groningen, PO Box 30.001, 9700 RB Groningen, The Netherlands. +31 503614071 (phone); +31 503614087 (fax); m.n.de.hooge@umcg.nl (e-mail).

Running Title: Biodistribution of ${ }^{89}$ Zr-MSLN HLE BiTE Word count: 5728 / 5000 
Disclosure of Potential Conflicts of Interest: The work performed in this study is cofinanced by the PPP-subsidy of the Top consortia for Knowledge and Innovation of the Ministry of Economic Affairs. G. Lorenczewski holds ownership interest in Amgen. J.M. Bailis holds ownership interest (including patents) in Amgen. S. Stienen holds ownership interest (including patents) in Amgen. M. Friedrich holds ownership interest (including patents) in Amgen. F. Lee holds ownership interest in Amgen. B. van der Vegt reports Institutional Financial Support for his advisory role from Visiopharm. E.G.E de Vries reports Institutional Financial Support for her advisory role from Sanofi, Pfizer, Daiichi Sankyo, NSABP, Merck and Institutional Financial Support for clinical trials or contracted research from Amgen, Genentech, Roche, Chugai Pharma, Synthon, CytomX Therapeutics, Nordic Nanovector, Regeneron, G1 Therapeutics, AstraZeneca, Radius Health, Bayer.

The other authors disclosed no potential conflicts of interest. 


\section{ABSTRACT}

$\mathrm{BiTE}^{\circledR}$ (bispecific T-cell engager) molecules exert antitumor activity by binding one arm to CD3 on cytotoxic T-cells and the other arm to a tumor-associated antigen. We generated a fully mouse cross-reactive mesothelin (MSLN)-targeted BiTE molecule that is genetically fused to a Fc-domain for half-life extension (HLE), and evaluated biodistribution and tumor targeting of a zirconium-89 ( $\left.{ }^{89} \mathrm{Zr}\right)$-labeled MSLN HLE BiTE molecule in 4T1 breast cancer bearing syngeneic mice with positron emission tomography (PET).

Biodistribution of $50 \mu \mathrm{g}{ }^{89} \mathrm{Zr}-\mathrm{MSLN}$ HLE BiTE was studied over time by PET imaging in $\mathrm{BALB} / \mathrm{c}$ mice and revealed uptake in tumor and lymphoid tissues with an elimination halflife of 63.4 hours. Compared to a non-targeting ${ }^{89}$ Zr-control HLE BiTE, the ${ }^{89} \mathrm{Zr}$-MSLN HLE BiTE showed a 2-fold higher tumor uptake and higher uptake in lymphoid tissues. Uptake in the tumor colocalized with mesothelin expression, while uptake in the spleen colocalized with CD3 expression. Evaluation of the effect of protein doses on the biodistribution and tumor targeting of ${ }^{89} \mathrm{Zr}$-MSLN HLE BiTE revealed for all dose groups that uptake in the spleen was faster than in the tumor (day 1 vs day 5). The lowest dose of $10 \mu \mathrm{g}{ }^{89} \mathrm{Zr}$-MSLN HLE BiTE had higher spleen uptake and faster blood clearance compared to higher doses of $50 \mu \mathrm{g}$ and $200 \mu \mathrm{g} .{ }^{89} \mathrm{Zr}-\mathrm{MSLN}$ HLE BiTE tumor uptake was similar at all doses.

Conclusions: The MSLN HLE BiTE showed specific tumor uptake and both arms contributed to the biodistribution profile. These findings support the potential for clinical translation of HLE BiTE molecules.

Keywords: Half-Life Extended Bispecific T-cell Engager (HLE BiTE) molecule, PETimaging, bispecific antibody, syngeneic mouse model, cancer-immunotherapy 


\section{INTRODUCTION}

T-cell engaging bispecific constructs are a novel form of cancer immunotherapy (1). They engage T-cells to tumors, leading to T-cell mediated tumor-cell killing irrespective of T-cell clonality. The number of T-cell engaging bispecific constructs has been increasing over the last years, with 38 constructs in clinical oncology trials in 2019 $(2,3)$.

BiTE $^{\circledR}$ (bispecific T-cell engager) molecules are T-cell engaging bispecific constructs of approximately $53 \mathrm{kDa}$ that exist as two single-chain variable fragments (scFv) connected by a short linker (4). One scFv binds T-cells via the CD3 receptor, and the other scFv binds the tumor cell via a tumor-associated antigen. Blinatumomab, a BiTE molecule targeting CD19 and CD3 has been approved by the Food and Drug Administration and European Medicine Agency for the treatment of B-cell acute lymphoblastic leukemia. Other BiTE molecules are in clinical evaluation (2,5-7). BiTE molecules show rapid clearance with a serum half-life of a few hours $(8,9)$ To maintain therapeutic serum concentrations, they are administered via continuous intravenous infusion.

To prolong plasma half-life and allow less frequent dosing, BiTE molecules have been genetically fused to an Fc-domain. This results in a half-life extended (HLE) BiTE molecule with a molecular weight of approximately 106 kDa (Supplementary Fig. 1A) $(10,11)$. In non-human primates, HLE BiTE molecules showed an extended serum halflife compatible with intermittent dosing (11).

Studies in immunocompetent mice showed the complexity of the biodistribution of T-cell engaging bispecific constructs. Increasing the affinity for CD3 of a CLL-1 T-cell engaging bispecific antibody reduced its plasma half-life (12). A high affinity CD3-targeting 
murine EpCAM BiTE molecule showed high lymphoid uptake and low tumor uptake (13). Moreover, uptake of HER2 T-cell engaging bispecific antibodies was higher in lymphoid tissues and lower in the tumor when CD3 affinity increased (14). Biodistribution of the CEA-targeted BiTE molecule ${ }^{89} \mathrm{Zr}$-AMG 211 was evaluated in patients with gastrointestinal adenocarcinomas. Positron emission tomography (PET) showed uptake in tumor lesions, although at moderate levels, as well as in lymphoid organs (9).

Currently, eight HLE BiTE molecules are in clinical trials of which four in solid tumors (NCT03319940, NCT03792841, NCT04117958, NCT04260191) (15). Increasing the half-life and molecular weight of a protein might influence the biodistribution and improve tumor targeting $(16,17)$. There is little data regarding the biodistribution and tumor targeting of HLE BiTE molecules. Therefore, we aimed to explore this preclinically with whole-body molecular imaging using PET and ex-vivo analyses.

We used an HLE BiTE molecule targeting murine CD3 and murine mesothelin (MSLN HLE BiTE) that we radiolabeled with PET isotope zirconium-89 $\left({ }^{89} \mathrm{Zr}\right) .{ }^{89} \mathrm{Zr}$ is an attractive PET isotope due its long half-life (78.4 hours) and efficient labeling to proteins (18).

Mesothelin is an attractive therapeutic target due to its high expression on the cell surface of several human cancers, including mesothelioma, ovarian cancer, pancreatic adenocarcinoma, and triple-negative breast cancer (19). Mesothelin expression on normal cells is primarily in the mesothelial cell layer (19). MSLN HLE BiTE molecules have been reported and multiple mesothelin-targeted drugs are currently in development (19-23).

Here, we report the biodistribution of the ${ }^{89} \mathrm{Zr}$-labeled murine MSLN HLE BiTE molecule in tumor-bearing syngeneic mice compared to a non-targeting control HLE BiTE molecule. 


\section{MATERIALS AND METHODS}

\section{HLE BiTE Molecules and Cell Lines}

A mouse cross-reactive MSLN scFv was generated using the commercially available mouse anti-mesothelin antibody MN-1 (Rockland; 200-301-A88), and affinity matured to increase mesothelin binding. The muMSLN scFv was attached by a short linker to mouse CD3 and a mouse cross-reactive Fcy-silenced Fc-domain (24), resulting in the mouse MSLN HLE BiTE molecule. For a non-targeting HLE BiTE molecule, a BiTE molecule targeting human EpCAM and human CD3 was fused to a Fcy-silenced human Fc. Amgen provided the murine MSLN HLE BiTE molecule and the control HLE BiTE molecule.

The conjugation to tetrafluorophenol- $N$-succinyl-desferrioxamine-Fe (TFP- $N$-sucDFO-Fe; $A B X)$ and labeling with ${ }^{89} \mathrm{Zr}$ of the HLE BiTE molecules is described in the supplemental data $(13,25)$. Labeling of the HLE BiTE molecules with ${ }^{89} \mathrm{Zr}$ resulted in [ ${ }^{89} \mathrm{Zr}$ ]Zr-DFO-N-suc-HLE BiTE molecules ( ${ }^{89} \mathrm{Zr}$-HLE BiTE molecules).

The mesothelin-positive murine mammary carcinoma cell line 4T1 (ATCC) was cultured in RPMI-1640 medium (Invitrogen) containing 10\% fetal calf serum (Bodinco BV). Cells were used between passages 5 and 20 after thawing and cultured under aseptic conditions at $37{ }^{\circ} \mathrm{C}$ in an incubator providing a humidified atmosphere of $5 \% \mathrm{CO}_{2}$. The cells were routinely tested for the presence of mycoplasma.

\section{Animal experiments}

All animal experiments were approved by the Institutional Animal Care and Use Committee of the University of Groningen. Eight to 10 weeks old female BALB/c mice (BALB/cOlaHsd, Envigo) were injected with $5 \times 10^{4} 4 \mathrm{~T} 1$ cells in $50 \mu \mathrm{L}$ RPMI-1640 in the 
lower mammary fat pad after 1 week of acclimatizing. Mice were allocated randomly to the groups.

Tracers $(4-5 \mathrm{MBq})$ were retro-orbitally injected when tumors reached approximately $200 \mathrm{~mm}^{3}$. Retro-orbital injections were chosen due to the similar distribution to tail vein intravenous, with no increased discomfort, and facile execution $(26,27)$. Mice were anesthetized with isoflurane/medical air inhalation (5\% induction, $2.5 \%$ maintenance) during all procedures. Whole-body radioactivity in the mice was measured with a calibrated dose-calibrator (Comecer).

MicroPET scans were acquired with the Focus220 rodent scanner (CTI Siemens). The data was reconstructed as previously described (28).

Scans were analyzed with PMOD (version 4.004, PMOD Technologies). Volumes of interest (VOIs) were drawn as spheres based on weight of organs found in the biodistribution. Data is expressed as mean standardized uptake value (SUVmean).

PET scans are visualized as maximum intensity projections scaled to the same maximum, allowing comparison between groups. Blood elimination half-life was calculated using one-phase decay (GraphPad, Prism 7).

The in-vivo biodistribution of $50 \mu \mathrm{g}{ }^{89} \mathrm{Zr}$-MSLN HLE BiTE was visualized in 8 tumorbearing BALB/c mice by microPET scans at 1, 3, 5, 7 and 9 days after injection. This dose was based on previous experience with immune cell targeting tracers (29).

The effect of the protein dose on the biodistribution and specific uptake of ${ }^{89} \mathrm{Zr}$ MSLN HLE BiTE was investigated by comparing 10, 50, $200 \mu \mathrm{g}{ }^{89} \mathrm{Zr}-\mathrm{MSLN}$ HLE BiTE and $50 \mu \mathrm{g}{ }^{89} \mathrm{Zr}$-control HLE BiTE on 1,3 and 5 days after injection. After the last imaging timepoint, an ex-vivo biodistribution was performed. All dose groups had 6 tumor-bearing BALB/c mice. Organs of interest and tumor were collected, weighed and measured in a 
calibrated Wizard gamma counter (PerkinElmer). Axillary lymph nodes were discarded from further analysis since their low weight resulted in highly variable values. Counts of known standards were used to convert counts into injected dose. Tissue radioactivity is expressed as percentage injected dose per gram (\%ID/g). Relevant tissues were fixed in formalin and embedded in paraffin for further analysis.

\section{Ex-Vivo Tissue Analysis}

Formalin-fixed paraffin-embedded blocks of tumor and spleen were sliced in $4 \mu \mathrm{m}$ sections. Tissue slides were exposed overnight to phosphor screens (PerkinElmer) in Xray cassettes. The imaging screens were read out by the Cyclone storage Phosphor System (PerkinEImer) and autoradiography images were analyzed with Image $1.52 p$ (US $\mathrm{NIH})$. These slides were stained with hematoxylin and eosin (H\&E) to assess tissue morphology. To quantify autoradiography data, regions of interest $(\mathrm{ROI})$ were identified in H\&E-stained slides. These regions were imported onto the autoradiography images and quantified. Values were normalized for activity injected.

In subsequent sections of the H\&E-stained slides, the presence of murine mesothelin and murine CD3 was visualized with immunohistochemical (IHC) staining. For murine $\mathrm{CD} 3$, after antigen retrieval of 15 minutes at $95{ }^{\circ} \mathrm{C}$ with a citrate buffer at $\mathrm{pH} 6$ a rabbit anti-mouse anti-CD3 antibody, clone: SP7 (Abcam; ab16669), was used in a 1:50 dilution. For mesothelin, antigens were retrieved in a Tris/HCl buffer at $\mathrm{pH} 9$ for 15 minutes incubation at $95{ }^{\circ} \mathrm{C}$ followed by overnight incubation with a rabbit anti-rabbit antimesothelin antibody (NSJ Bioreagents; R32262) in a 1:50 dilution. Thereafter, a peroxidase-conjugated goat anti-rabbit antibody (Dako) and 3-3'-diaminobenzidine (DAB) were added to visualize peroxidase activity. Necrotic areas on H\&E-stained liver sections were quantified in QuPath (30). With a limulus amebocyte lysate assay (Endosafe-PTS, 
Charles River), bacterial endotoxins were quantified in the parental and the conjugated MSLN HLE BiTE, and the final tracer solution.

The gastrointestinal tract was exposed overnight to a phosphor plate at $-20{ }^{\circ} \mathrm{C} 9$ days after injection of $50 \mu \mathrm{g}{ }^{89} \mathrm{Zr}$-MSLN HLE BiTE. Hereafter, sections of the tissue were embedded with TissueTek O.C.T compound (Sakura) and stained with H\&E.

\section{Statistical Methods}

SUV $V_{\text {mean }}$ PET scan data was expressed as mean \pm standard deviation. An analysis of variance (ANOVA) among uptake of multiple groups was followed by a post hoc Tukey's multiple comparison test. $P$ values $\leq 0.05$ were considered significant.

Ex-vivo biodistribution data is presented as median $\% \mathrm{ID} / \mathrm{g}$ with interquartile range. On this data, an ANOVA among uptake of multiple groups was performed with the Kruskal-Wallis test. When statistically significant differences were found, a post hoc Bonferroni corrected Mann-Whitney U-test was performed. Between a pair of groups, the similarity was tested with a Mann-Whitney U-test.

All statistical tests were performed in GraphPad, Prism 7. 


\section{RESULTS}

\section{Conjugation and Radiolabeling of HLE BiTE Molecules}

The binding affinity of the parental MSLN HLE BiTE was $3.0 \mathrm{nM}$ for mouse mesothelin expressed on 4T1 cells and $26.8 \mathrm{nM}$ for CD3 expressed on T-cells for mouse CD3 (Supplementary Fig. 1B and 1C). The 4T1 cell line expresses 5933 mesothelin molecules per cell (Supplementary Fig. 1D). This mesothelin expression is relatively low compared with ovarium carcinoma cell line OVCAR8 and other human mesothelinpositive cancer cell lines (Supplementary Fig. 1E) (20).

The parental MSLN HLE BiTE molecule engaged mouse T cells to kill 4T1 tumor cells, with half-maximal lysis of 29.15 pM (Supplementary Fig. 1F). MSLN HLE BiTE activity was specific for mesothelin-expressing cells, as no activity was observed against the mesothelin-negative cell line B16F10 (Supplementary Fig. 1G). The nontargeting control HLE BiTE molecule did not have activity against either 4T1 or B16F10 cells, as expected.

Conjugation on the HLE BiTE molecules resulted in HLE BiTE:DFO end ratios of 1:2.6 and 1:2.3, respectively. Conjugation of the MSLN HLE BiTE did not affect its ability to engage T-cells and target cells, shown by maintained in vitro cytotoxicity and T-cell activation (Supplementary Fig. 2A-C). Also, the conjugated MSLN HLE BiTE was intact with a single protein peak at $280 \mathrm{~nm}$ on the chromatogram (Supplementary Fig. 2D).

\section{PET Imaging of ${ }^{89} \mathrm{Zr}-\mathrm{MSLN}$ HLE BiTE over Time}

PET scanning after $50 \mu \mathrm{g}{ }^{89} \mathrm{Zr}$-MSLN HLE BiTE administration was performed at $1,3,5,7$, and 9 days, and revealed uptake in the tumor, spleen, thymus, and liver (Fig. 1A). Time to reach the maximum uptake varied for organs and tumor (Fig. 1B). Spleen uptake was already highest at day $1\left(S U V_{\text {mean }}=1.84 \pm 0.25\right)$ and decreased, while thymus 
uptake was maximal at day $3\left(S U V_{\text {mean }}=1.74 \pm 0.17\right)$ and remained stable thereafter. Maximum tumor uptake was reached at day $5\left(S U V_{\text {mean }}=1.50 \pm 0.21\right)$.

Organ-to-blood ratios increased between days 1 and 9 to $4.5 \pm 0.7$ for the thymus, $3.4 \pm 0.5$ for the tumor and $2.8 \pm 0.4$ for the spleen, since blood levels decreased (Fig. 1C). ${ }^{89} \mathrm{Zr}$-MSLN HLE BiTE blood elimination half-life, based on the heart blood pool, was 63.4 hours $(R=0.96)$. Day 5 was chosen to compare ex-vivo biodistribution, when organto-blood ratios were $2.1 \pm 0.3$ for the thymus, $1.9 \pm 0.3$ for the tumor and $1.7 \pm 0.2$ for the spleen.

\section{Dose-Dependent Biodistribution of ${ }^{89} \mathrm{Zr}-\mathrm{MSLN}$ HLE BiTE}

On day 1 after $10 \mu g$ 89 Zr-MSLN HLE BiTE administration a high spleen-to-blood ratio (ratio $=2.26 \pm 0.33$ ) visualized the spleen on PET scans, in contrast to the 50 and $200 \mu$ g groups (spleen-to-blood ratios $=1.26 \pm 0.15$ and $0.92 \pm 0.13$, respectively; Fig. $2 \mathrm{~A}$ and Supplementary Fig. 3A). Spleen SUVmean inversely correlated with protein dose, indicating target saturation (Fig. 2B). Blood SUVmean of the $10 \mu \mathrm{g}$ dose was lower than the higher doses. As a consequence, on day 5 tumor uptake of $10 \mu \mathrm{g}$ was lower than uptake of $50 \mu \mathrm{g}{ }^{89} \mathrm{Zr}$-MSLN HLE BiTE, but no difference between the tumor-to-blood ratios was found (Supplementary Fig. 3A). In the thymus, no relation between uptake and protein dose was seen (Fig. 2B). However, uptake of $50 \mu \mathrm{g}$ dose was increased compared to 10 $\mu \mathrm{g}$ and $200 \mu \mathrm{g}$.

Ex-vivo analysis on day 5 confirmed the PET findings, and revealed dosedependent uptake in the mesenteric lymph nodes (Fig. 2C and Supplementary Table 1).

Biodistribution of ${ }^{89} \mathrm{Zr}$-MSLN HLE BiTE compared to a Non-Targeting ${ }^{89} \mathrm{Zr}$-Control HLE BiTE Molecule 
Tumor SUVmean following $50 \mu \mathrm{g}{ }^{89} \mathrm{Zr}-\mathrm{MSLN}$ HLE BiTE increased from day 1 (1.40 $\pm 0.11)$ to $1.52 \pm 0.22$ at day 5 , while for $50 \mu \mathrm{g}{ }^{89} \mathrm{Zr}$-control HLE BiTE, tumor uptake decreased from day $1(0.91 \pm 0.14)$ to $0.77 \pm 0.11$ at day 5 (Fig. $3 \mathrm{~A}$ and $3 \mathrm{~B}) .{ }^{89} \mathrm{Zr}$-control HLE BiTE did not show uptake in spleen and thymus. Although blood levels obtained with both tracers were similar, whole-body radioactivity levels showed that the whole-body clearance of ${ }^{89} \mathrm{Zr}$-control HLE BiTE was faster compared to the ${ }^{89} \mathrm{Zr}$-MSLN HLE BiTE (Fig. $3 C)$.

Ex-vivo biodistribution at day 5 confirmed the similar blood levels and specific uptake of ${ }^{89} \mathrm{Zr}$-MSLN HLE BiTE in tumor, spleen, and thymus compared to the control HLE BiTE (Fig. 3D and Supplementary Table 2). ${ }^{89}$ Zr-MSLN HLE BiTE uptake was also higher than control in the liver, kidney, lung, adipose tissue, and gastrointestinal tract.

White spots on the liver were observed ex-vivo in the various ${ }^{89}$ Zr-MSLN HLE BiTE groups. H\&E-staining revealed areas of necrosis, while in the ${ }^{89} \mathrm{Zr}$-control HLE BiTE group the liver tissue was unaffected. Higher protein doses of ${ }^{89} \mathrm{Zr}-\mathrm{MSLN}$ HLE BiTE showed an increased area affected by necrosis. Endotoxin measurements of MSLN HLE BiTE and the conjugated stock, as well as the tracer solution, revealed no contaminations (Supplementary Fig. 4).

\section{Ex-Vivo Analysis of ${ }^{89} \mathrm{Zr}$-MSLN HLE BiTE Uptake by Autoradiography and Immunohistochemistry}

Autoradiography showed hotspots in the gastrointestinal tract of mice 9 days after receiving $50 \mu \mathrm{g}{ }^{89} \mathrm{Zr}-\mathrm{MSLN}$ HLE BiTE (Fig. 4A). H\&E staining of frozen sections identified the radioactivity localized in the gut-associated lymphoid nodes, consistent with binding of the tracer to T-cells (Fig. 4B). Examining the slides 9 days after injection might have 
increased signal over background over time injection (Figure 1). Radioactivity hotspots in the spleen, identified 5 days after tracer injection, colocalized with the white pulp (Fig. 5A). IHC-staining confirmed high CD3 expression in the white pulp, while mesothelin staining was negative. In contrast, for ${ }^{89} \mathrm{Zr}$-control HLE BiTE, no hotspots and only low homogeneous distribution were seen in the spleen. Quantification of autoradiography data confirmed the higher spleen uptake of ${ }^{89} \mathrm{Zr}$-MSLN HLE BiTE $(1747 \pm 109.8)$ compared to ${ }^{89} \mathrm{Zr}$-control HLE BiTE $(1009 \pm 59.6, P<0.01)$. It also showed the high ${ }^{89} \mathrm{Zr}$-MSLN HLE BiTE signal in the CD3-rich white pulp $(2763 \pm 119.2)$ versus the red pulp $(1516 \pm 86.9)$ (Supplementary Fig. 5). ${ }^{89} \mathrm{Zr}$-MSLN HLE BiTE autoradiography of the tumor showed that the radioactivity overlapped with mesothelin-expressing tumor tissue outside the necrotic core (Fig. 5B). The signal was not increased in tumor areas that contained CD3+ positive cells. ${ }^{89} \mathrm{Zr}$-control HLE BiTE uptake in tumor tissue was low, but higher local uptake matched with the small necrotic core (Fig. 5B, Supplementary Fig. 6). ${ }^{89} \mathrm{Zr}-\mathrm{MSLN}$ HLE BiTE autoradiography of tumor tissue with an adjacent lymph node showed radioactivity overlapping with CD3 expression in the lymph node and with mesothelin expression in the tumor. Interestingly, radioactivity in the adjacent lymph node was 2-fold higher than uptake in the tumor (Supplementary Fig. 7). 


\section{DISCUSSION}

This is the first biodistribution study with an HLE BiTE molecule. The MSLN HLE BiTE showed specific uptake in the tumor and lymphoid organs. Uptake of the tracer in the spleen and mesenteric lymph nodes was dose-dependent. MSLN HLE BITE localized to the gut in the adjacent lymph nodes. Both targeting arms clearly contributed to MSLN HLE BiTE biodistribution, with spleen uptake correlating to the CD3 expression while tumor uptake related to mesothelin expression.

Two variables changed with the MSLN HLE BiTE compared to the previously evaluated first-generation BiTE molecules. The half-life is extended by fusing the BiTE molecule to an Fc-domain, and the affinity for the tumor-associated antigen (mesothelin, $\left.\mathrm{K}_{d}=3.0 \mathrm{nM}\right)$ is higher than for CD3 $\left(\mathrm{K}_{d}=26.8 \mathrm{nM}\right)$. Our study shows that these modifications induced important differences in the biodistribution. Biodistribution of the first-generation BiTE molecule muS110, targeting mouse EpCAM $\left(K_{d}=21 \mathrm{nM}\right)$ and mouse CD3 $\left(K_{d}=2.9 \mathrm{nM}\right)$, was driven by its CD3 arm (13). For the MSLN HLE BiTE molecule, both arms contribute to its biodistribution. Intratumoral uptake co-localized with mesothelin expression and the maximum tumor uptake of MSLN HLE BiTE was 6-fold higher than for muS110. Moreover, this maximum uptake was reached later, namely on day 5 versus 6 hours after administration. Other first-generation BiTE molecules also had lower tumor uptake in biodistribution studies in nude mice bearing human tumors. Depending on the BiTE molecule and tumor model used, uptake varied between 4 - $8 \%$ ID/g 24 hours after administration $(28,31)$.

Spleen uptake co-localized with CD3 presence in the white pulp. The Fcy silent Fcdomain of MSLN HLE BiTE, and uptake in T-cell rich white pulp versus lower uptake in the macrophage-rich red pulp render Fc-mediated spleen uptake if present minimal. We 
found that 5933 mesothelin molecules are expressed per 4T1 cell, while CD3 is generally expressed around $10^{5}$ CD3 molecules per human T-cell $(32,33)$. In the spleen, this high CD3 expression possibly acts as a first "sink". This organ which functions as the primary filter for the blood, has leaky discontinuous capillaries that permit fast accumulation $(34,35)$. A dose of $10 \mu \mathrm{g}$ resulted in immediate high spleen uptake, low blood levels and moderate tumor uptake. This rapid uptake seems to limit the available HLE BiTE molecules in the circulation. A small increase of the protein dose from 10 to $50 \mu \mathrm{g}$ resulted in reduced spleen uptake, higher blood levels and higher tumor uptake. Increasing the dose to $200 \mu \mathrm{g}$ further reduced spleen uptake, but it did not further increase tumor uptake, possibly due to binding saturation. Dose-dependent uptake was not observed in the thymus, also uptake in the thymus was slower compared to the spleen. In contrast to the spleen, the thymus has continuous capillaries limiting blood extravasation from the vasculature (36). Both thymus and spleen have extensive availability of CD3+ T-cells, but dose-dependent uptake is observed just in the spleen. The 9-fold higher affinity of the MSLN HLE BiTE molecule for mesothelin may drive uptake in the tumor, but the uptake seems influenced by the availability in the blood after rapid 'clearance'.

Ex-vivo biodistribution revealed that ${ }^{89} \mathrm{Zr}$-MSLN HLE BiTE uptake was higher in multiple organs such as the liver, kidney, lung, adipose tissue, and the gastrointestinal tract compared to the control HLE BiTE. A slightly higher uptake in liver and kidney is also found for radiolabeled anti-mesothelin antibodies compared to other antibodies in humans $(37,38)$. Higher uptake observed in lung, adipose tissue, and heart is consistent with RNA expression profiles of mesothelin (39). The gastrointestinal tract uptake of ${ }^{89} \mathrm{Zr}-\mathrm{MSLN}$ HLE BiTE is CD3-mediated with uptake in the gut-associated lymph nodes. Specific immune 
cell-mediated uptake in the gut has been previously observed for a murine CD8+ T-cell tracer and a radiolabeled BiTE molecule targeting CD3+ T-cells $(13,40)$.

Unexpectedly, the livers of mice receiving ${ }^{89} \mathrm{Zr}-\mathrm{MSLN}$ HLE BiTE showed an increase in necrotic areas, which was tracer dose-dependent while the liver does not express mesothelin $(19,39)$. The buffer components were similar, and we ruled out endotoxin toxicity as a cause but have yet to find an explanation for this observation. Further investigation is beyond the scope of this study.

In the clinic, BiTE molecules are administered continuously intravenously, given their short half-life. In a PET-imaging study with ${ }^{89} \mathrm{Zr}-\mathrm{AMG} 211$ in patients with gastrointestinal adenocarcinomas, rapid renal clearance, and relatively low tumor uptake were observed (9). With the extended half-life of HLE BiTE molecules, less frequent administrations and higher tumor uptake are projected. Multiple HLE BiTE molecules are currently being evaluated, and most have a similar affinity balance between CD3 and the tumor-associated antigen as the MSLN HLE BiTE evaluated here (AMG 160, PSMA (Kd $=14.8 \mathrm{nM})$ and CD3 $\left(\mathrm{K}_{d}=22.4 \mathrm{nM}\right)$, and AMG 757, DLL3 $\left(\mathrm{K}_{\mathrm{d}}=0.64 \mathrm{nM}\right)$ and CD3 $\left(\mathrm{K}_{d}=\right.$ $14.9 \mathrm{nM}))(41,42)$.

Increasing the blood half-life of tumor-targeting antibody constructs raises the tumor uptake in mice (17). The effect of increasing tumor affinity on tumor uptake is less straightforward (16). A theoretical peak in maximum uptake seems to exist, where a lower affinity will prevent accumulation, and increasing the affinity will hamper tumor penetration and accumulation $(16,43)$. Therefore, we hypothesize that the extended half-life is mainly responsible for the increase in tumor uptake of the MSLN HLE BiTE compared to canonical BiTE molecules. 
The contribution of each targeting arm of a bispecific antibody construct to its biodistribution, is complex to predict. Our results indicate that the circulatory half-life of the construct plays an important role in this biodistribution. In this study, molecular imaging demonstrates that MSLN HLE BiTE biodistribution is driven by both targeting arms and has improved pharmacokinetic parameters over BiTE molecules. These findings support the future clinical development of HLE BiTE molecules and the use of molecular imaging in this process to understand biodistribution and tumor targeting.

\section{Acknowledgments}

The authors would like to thank at the UMCG Jürgen Sijbesma for support with animal handling and Linda Pot-de Jong for assistance with the immunohistochemical staining.

\section{Key points}

Question: How is the whole-body biodistribution and tumor-targeting of half-life extended bispecific T-cell engager molecules (HLE BiTE) in tumor-bearing syngeneic mice?

Pertinent findings: This biodistribution study with a zirconium- $89\left({ }^{89} \mathrm{Zr}\right)$ labeled mesothelin (MSLN)-targeted HLE BiTE molecule and a ${ }^{89} \mathrm{Zr}$-control HLE BiTE molecule revealed specific tumor uptake and both targeting arms of the MSLN HLE BiTE molecule contributing to its biodistribution. The MSLN HLE BiTE molecule accumulates at mesothelin and CD3 expressing tissues, such as the tumor and the spleen. 
Implications for patient care: Multiple HLE BiTE molecules are currently in clinical trials. This study in mice shows their favorable biodistribution profile and supports the potential for clinical translation of HLE BiTE molecules. 


\section{REFERENCES}

1. Carter PJ, Lazar GA. Next generation antibody drugs: pursuit of the 'high-hanging fruit'. Nat Rev Drug Discov. 2018;17:197-223.

2. Suurs FV, Lub-de-Hooge MN, de Vries EGE, et al. A review of bispecific antibodies and antibody constructs in oncology and clinical challenges. Pharmacol Ther. 2019;201:103-19.

3. Labrijn AF, Janmaat ML, Reichert JM, et al. Bispecific antibodies: a mechanistic review of the pipeline. Nat Rev Drug Discov. 2019;18:585-608.

4. Mack M, Riethmuller G, Kufer P. A small bispecific antibody construct expressed as a functional single-chain molecule with high tumor cell cytotoxicity. Proc Natl Acad Sci USA. 1995;92:7021-25.

5. Klinger M, Benjamin J, Kischel R, et al. Harnessing $\mathrm{T}$ cells to fight cancer with

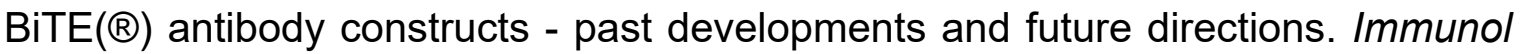
Rev. 2016;270:193-208.

6. Topp MS, Duell J, Zugmaier G, et al. Anti-B-cell maturation antigen BiTE molecule AMG 420 induces responses in multiple myeloma. J Clin Oncol. 2020;38:775-83.

7. Hummel HD, Kufer P, Grüllich $C$, et al. Phase 1 study of pasotuxizimab (BAY 2010112), a PSMA-targeting bispecific T-cell engager (BiTE) immunotherapy for metastatic castration-resistant prostate cancer (mCRPC) [abstract]. J Clin Oncol. 2019;37:15 Suppl (Abstract 5034).

8. Zhu M, Wu B, Brandl C, et al. Blinatumomab, a bispecific T-cell engager (BiTE®) for CD-19 targeted cancer immunotherapy: clinical pharmacology and its implications. Clin Pharmacokinet. 2016;55:1271-88. 
9. Moek KL, Waaijer SJH, Kok IC, et al. ${ }^{89} \mathrm{Zr}$-labeled bispecific T-cell engager AMG 211 PET shows AMG 211 accumulation in CD3-rich tissues and clear, heterogeneous tumor uptake. Clin Cancer Res. 2019;25:3517-27

10. Arvedson TL, Balazs M, Bogner P, et al. Generation of half-life extended antiCD33 BiTE® antibody constructs compatible with once-weekly dosing [abstract]. Cancer Res. 2017;77:13 Suppl (Abstract 55).

11. Lorenczewski G, Friedrich M, Kischel R, et al. Generation of a half-life extended anti-CD19 BiTE antibody construct compatible with once-weekly dosing for treatment of CD19-positive malignancies [abstract]. Blood. 2017;130: 1 Suppl (Abstract 2815).

12. Leong SR, Sukumaran S, Hristopoulos M, et al. An anti-CD3/anti-CLL-1 bispecific antibody for the treatment of acute myeloid leukemia. Blood. 2017;129:609-18.

13. Suurs FV, Lorenczewski G, Stienen S, et al. Biodistribution of a CD3/EpCAM bispecific T-cell engager is driven by the CD3 arm. $J$ Nucl Med. 2020;61:15941601.

14. Mandikian D, Takahashi N, Lo AA, et al. Relative target affinities of T-celldependent bispecific antibodies determine biodistribution in a solid tumor mouse model. Mol Cancer Ther. 2018;17:776-85.

15. Einsele H, Borghaei, H, Orlowski RZ, et al. The BiTE (Bispecific T-cell Engager) platform: Development and future potential of a targeted immune-oncology therapy across tumor types. Cancer. 2020;126:3192-201.

16. Warnders FJ, Lub-de Hooge $M N$, de Vries EGE, et al. Influence of protein properties and protein modification on biodistribution and tumor uptake of 
anticancer antibodies, antibody derivatives, and non-Ig scaffolds. Med Res Rev. 2018;38:1837-73.

17. Stork R, Campigna E, Robert B, et al. Biodistribution of a bispecific single-chain diabody and its half-life extended derivatives. J Biol Chem. 2009;284:25612-19.

18. Heskamp S, et al. ${ }^{89} \mathrm{Zr}$-Immuno-Positron Emission Tomography in Oncology: Stateof- the-Art 89Zr Radiochemistry. Bioconjugate Chem. 2017;28:2211-2223.

19. Hassan R, Thomas A, Alewine C, et al. Mesothelin immunotherapy for cancer: ready for prime time? J Clin Oncol. 2016;34:4171-79.

20. Sternjak A, Lee F, Wahl J, et al. Preclinical evaluation of a BiTE® antibody construct with extended half-life that targets the tumor differentiation marker mesothelin [abstract]. Cancer Res. 2017;77:13 Suppl (Abstract 3630).

21. Jurcak NR, Zarecki M, Lee $F$, et al. Evaluation of mesothelin BiTE $®$ antibody constructs in models of pancreatic ductal adenocarcinoma [abstract]. Cancer Res. 2019;79:13 Suppl (Abstract 1561).

22. Hassan R, et al. First-in-Human, Multicenter, Phase I Dose-Escalation and Expansion Study of Anti-Mesothelin Antibody-Drug Conjugate Anetumab Ravtansine in Advanced or Metastatic Solid Tumors. J Clin Oncol. 2020;38:18241835.

23. Morello A, Sadelain M, Adusumilli PS. Mesothelin-targeted CARs: driving T cells to solid tumors. Cancer Discov. 2016;6:133-46

24. Jacobsen FW, Stevenson R, Li C, et al. Engineering an IgG scaffold lacking effector function with optimized developability. J Biol Chem. 2017;292:1865-75. 
25. Verel I, Visser GWM, Boellaard R, et al. ${ }^{89} \mathrm{Zr}$ immuno-PET: comprehensive procedures for the production of ${ }^{89} \mathrm{Zr}$-labeled monoclonal antibodies. J Nucl Med. 2003;44:1271-81.

26. Steel CD, et al. Comparison of the lateral tail vein and the retro-orbital venous sinus as routes of intravenous drug delivery in a transgenic mouse model. Lab Anim (NY). 2008; 37:26-32.

27. Yardeni T, et al. Retro-orbital injections in mice. Lab Anim (NY). 2011:40:155-60.

28. Warnders FJ, Waaijer SJH, Pool M, et al. Biodistribution and PET imaging of labeled bispecific T cell-engaging antibody targeting EpCAM. J Nucl Med. 2016;57:812-7.

29.van der Veen EL, Giesen D, Pot-de Jong $L$, et al. ${ }^{89} \mathrm{Zr}$-pembrolizumab biodistribution is influenced by PD-1-mediated uptake in lymphoid organs. $J$ Immunother Cancer. 2020;2:e000938.

30. Bankhead P, Loughrey MB, Fernandez JA, et al. QuPath: open source software for digital pathology image analysis. Sci Rep. 2017;7:16878.

31. Waaijer SJH, Warnders FJ, Stienen S, et al. Molecular imaging of radiolabeled bispecific T-cell engager ${ }^{89} \mathrm{Zr}$-AMG211 targeting CEA-positive tumors. Clin Cancer Res. 2018;24:4988-96.

32. El Hentati FZ, Gruy F, lobagiu C, et al. Variability of CD3 membrane expression and T cell activation capacity. Cytometry B Clin Cytom. 2010;78:105-114.

33. Ginaldi L, Matutes E, Farahat N, et al. Differential expression of CD3 and CD7 in T-cell malignancies: a quantitative study by flow cytometry. $\mathrm{Br} J$ Haematol. 1996,93:921-7. 
34. Bronte $\mathrm{V}$ and Pittet $\mathrm{M}$. The spleen in local and systemic regulation of immunity. Immunity. 2013;39:806-18.

35. Cataldi M, Vigliotti C, Mosca T, et al. Emerging role of the spleen in the pharmacokinetics of monoclonal antibodies, nanoparticles and exosomes. Int J Mol Sci. 2017;18:1249.

36. Pavelka M, Roth J. Functional Ultrastructure: Atlas of Tissue Biology and Pathology. Vienna, Austria: Springer Vienna; 2010:198, 294-298.

37. Lamberts LE, Menke-van der Houven van Oordt CW, ter Weele EJ, et al. ImmunoPET with anti-mesothelin antibody in patients with pancreatic and ovarian cancer before anti-mesothelin antibody-drug conjugate treatment. Clin Cancer Res. 2015;22:1642-52.

38. Bensch F, Smeenk MM, van Es SC, et al. Comparative biodistribution analysis across four different ${ }^{89} \mathrm{Zr}$-monoclonal antibody tracers - The first step towards an imaging warehouse. Theranostics. 2018;8:4295-304.

39. Uhlén M, Fagerberg L, Hallström BM, et al. Tissue-based map of the human proteome. Science. 2015;347:1260419.

40. Seo JW, Tavaré R, Mahakian LM, et al. CD8+ T-cell density imaging with ${ }^{64} \mathrm{Cu}$ labeled cys-diabody informs immunotherapy protocols. Clin Cancer Res. 2018;24:4976-87.

41. Bailis J, Deegen P, Thomas O, et al. Preclinical evaluation of AMG 160, a nextgeneration bispecific $\mathrm{T}$ cell engager (BiTE) targeting the prostate-specific membrane antigen PSMA for metastatic castration-resistant prostate cancer (mCRPC) [abstract]. J Clin Oncol. 2019;37:7 Suppl (Abstract 301). 
42. Giffen M, Cooke K, Lobenhofer EK, et al. AMG 757, a Half-Life Extended, DLL3targeted Bispecific T-Cell Engager, shows high potency and sensitivity in preclinical models of small cell lung cancer. Clin Cancer Res. November 17, 2020 [Epub ahead of print].

43. Thurber GM, Schmidt MM, Wittrup KD. Antibody tumor penetration: transport opposed by systemic and antigen-mediated clearance. Adv Drug Deliv Rev. 2008;60:1421-34. 


\section{FIGURE LEGENDS}

A

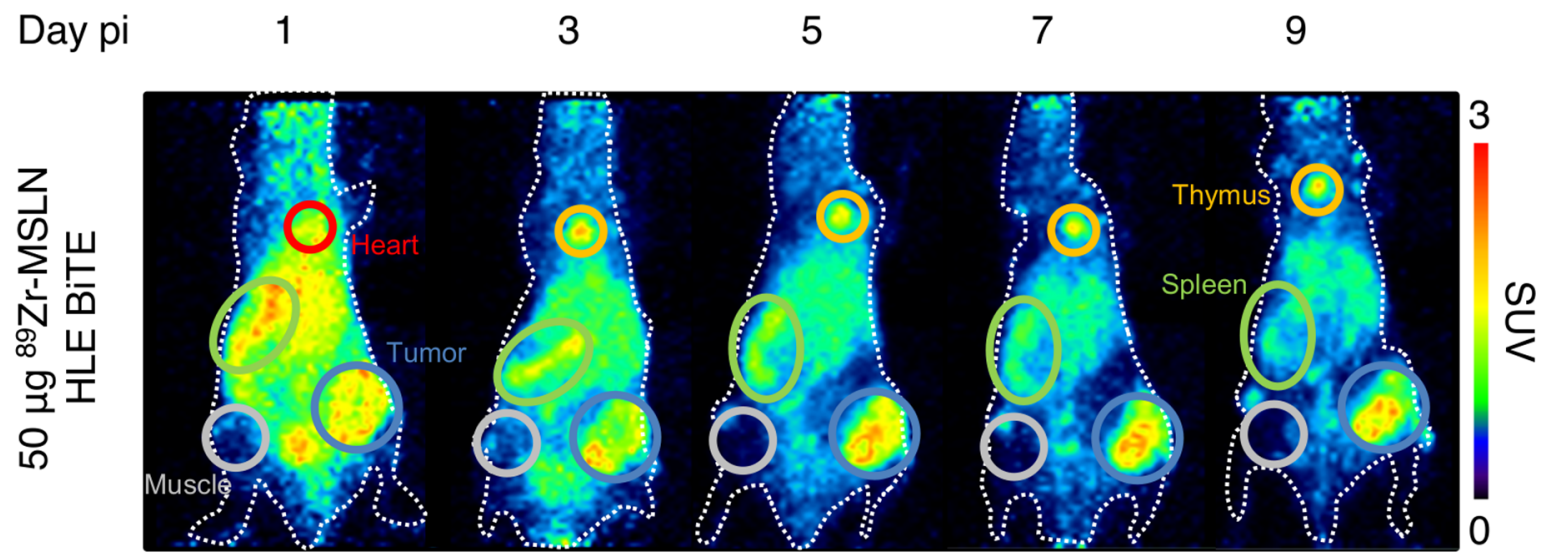

B

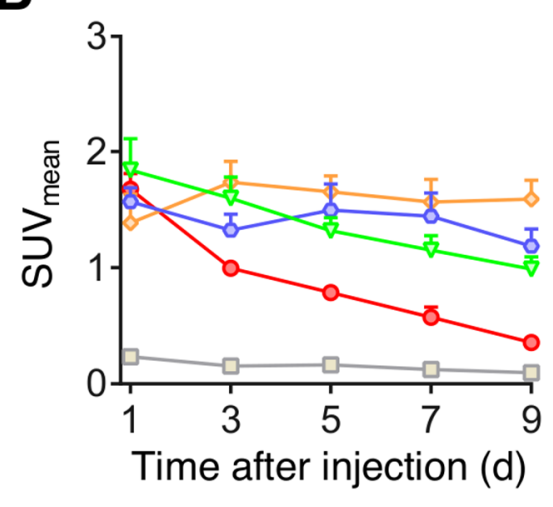

C

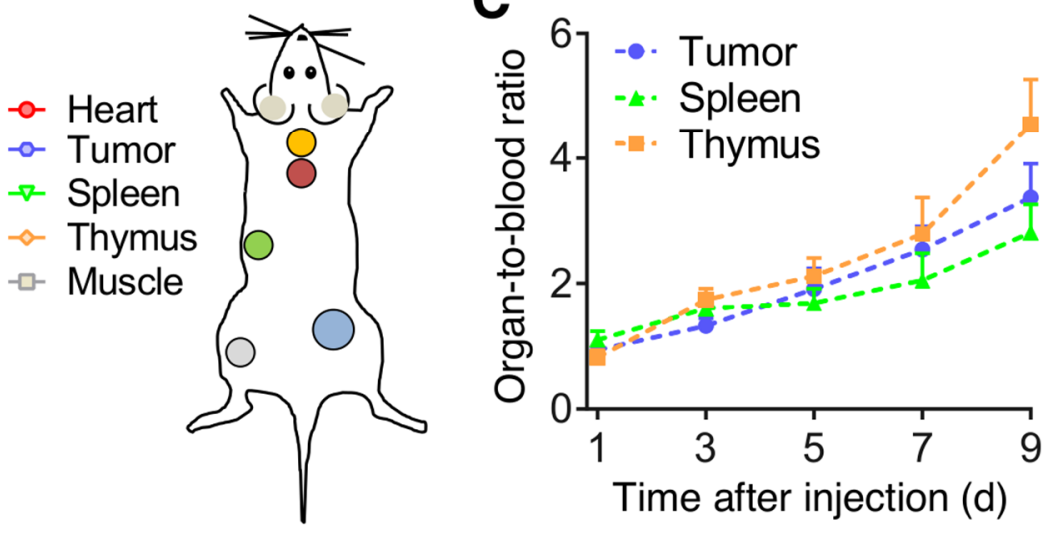

Figure 1. PET scans over time after administration of $50 \mu \mathrm{g}{ }^{89} \mathrm{Zr}-\mathrm{MSLN}$ HLE BiTE in 4T1tumor-bearing mice $(n=8)$. A, Representative maximum intensity projections of PET images up to 9 days post tracer injection. Encircled are spleen (green), heart (red), tumor (blue) and thymus (yellow). B, Image quantification of heart, tumor, spleen, thymus and muscle expressed as SUV mean. C, Image quantification expressed as organ-to-blood ratios. Data is presented as mean \pm standard deviation. 
A
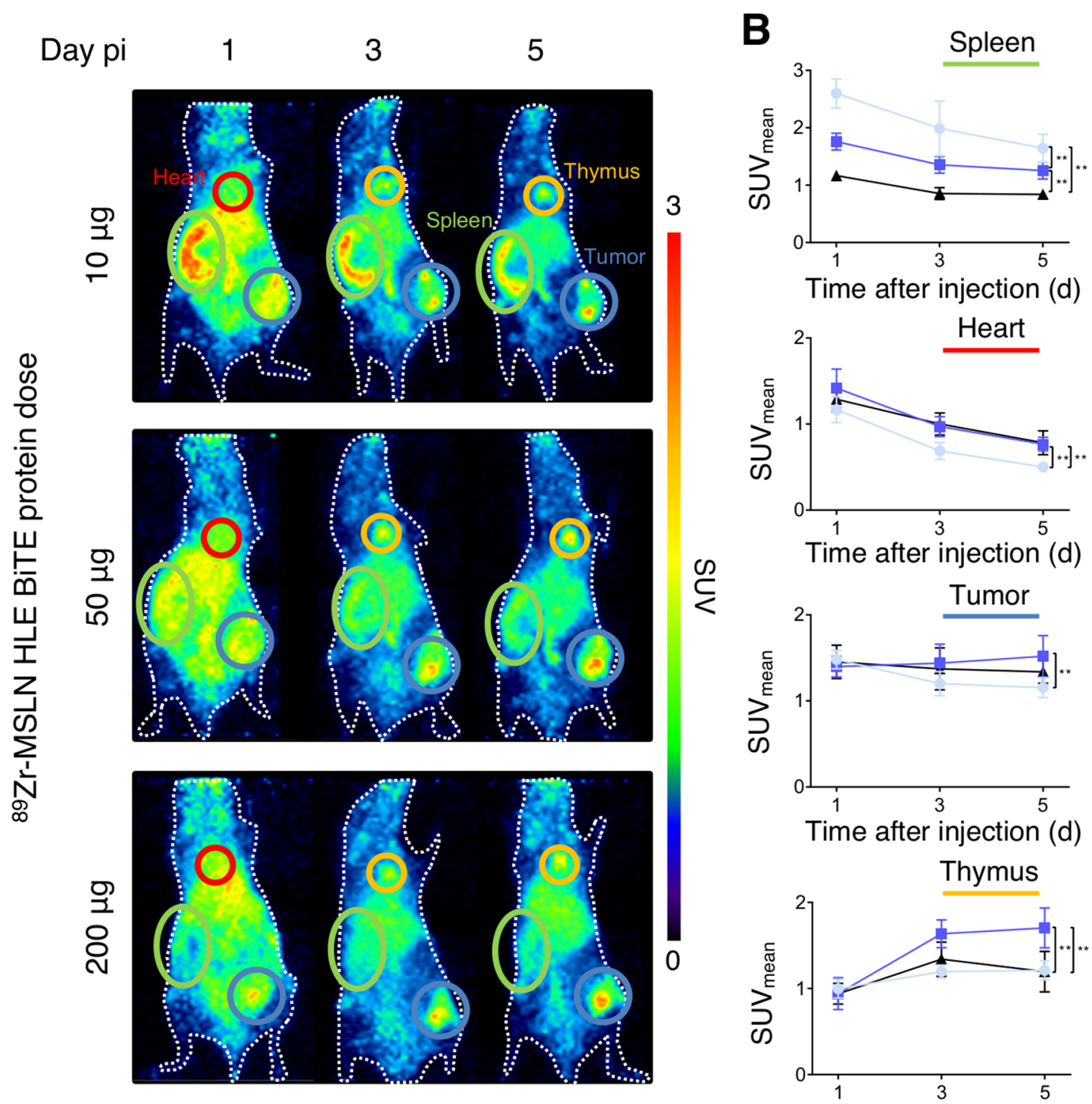

C

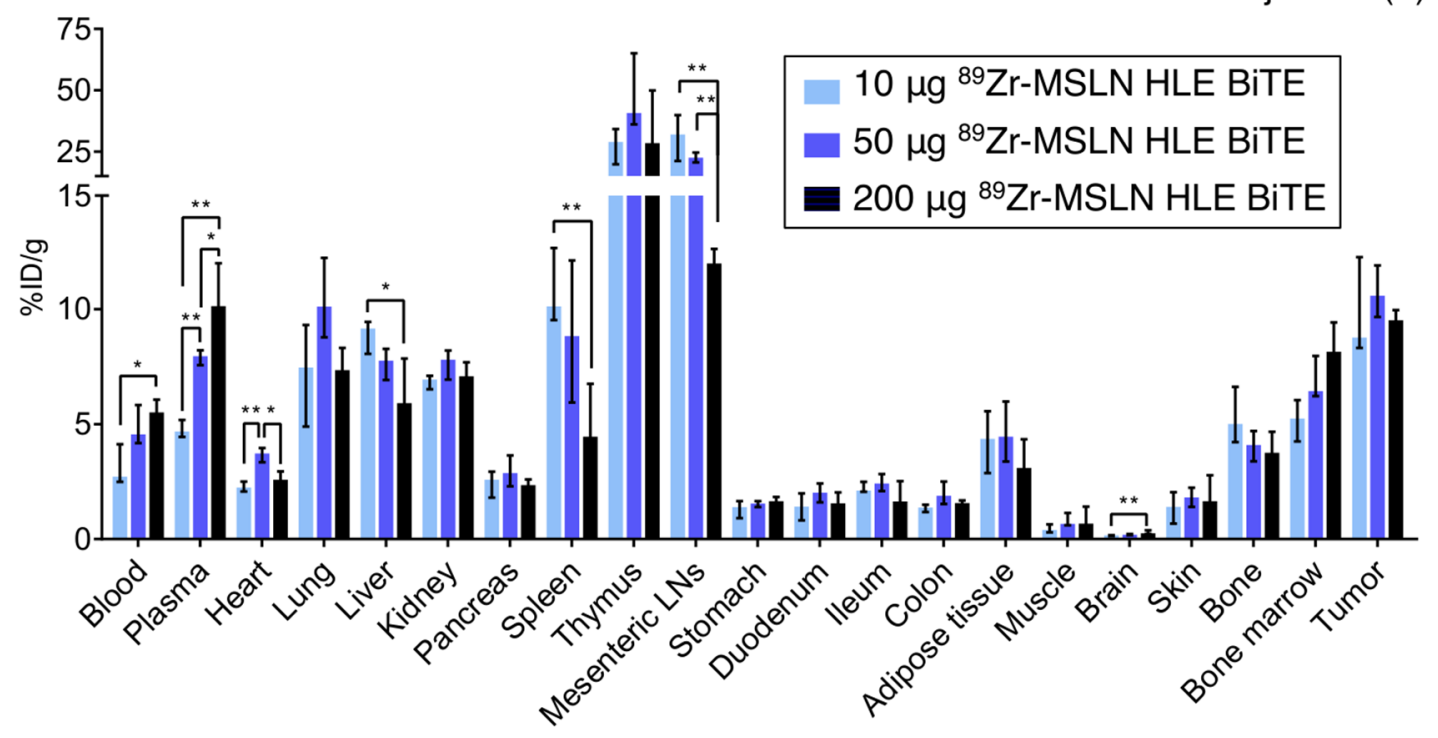


Figure 2. Dose-dependent biodistribution of ${ }^{89} \mathrm{Zr}-\mathrm{MSLN}$ HLE BiTE in 4T1-tumor-bearing mice. A, Representative maximum intensity projections of PET images of 1,3 and 5 days post injection of 10,50 or $200 \mu g$ 89 Zr-MSLN HLE BiTE ( $n=6$ for 10 and $50 \mu g$ dose, $n=$ 5 for $200 \mu \mathrm{g}$ dose). Encircled are spleen (green), heart (red), tumor (blue) and thymus (yellow). B, PET quantification of spleen, heart, tumor and thymus, data presented as mean \pm standard deviation. C, Ex-vivo biodistribution with data presented as median with interquartile range; *: $P \leq 0.05,{ }^{* *}: P \leq 0.01$. 
A

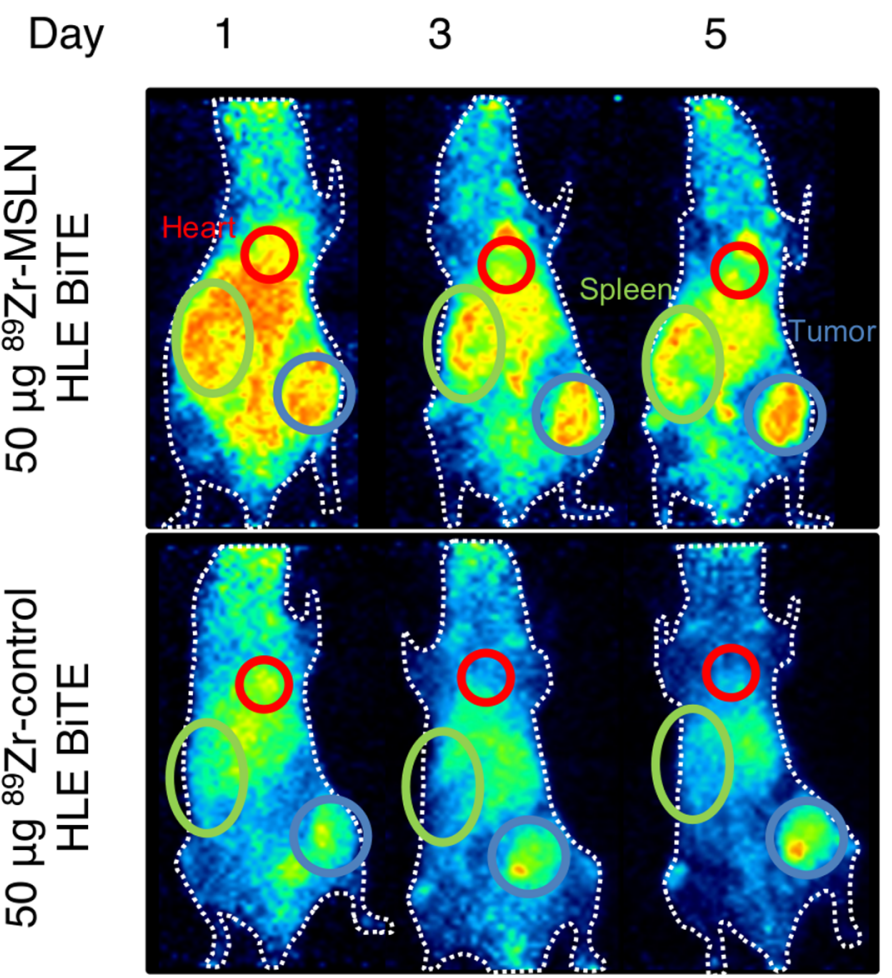

B

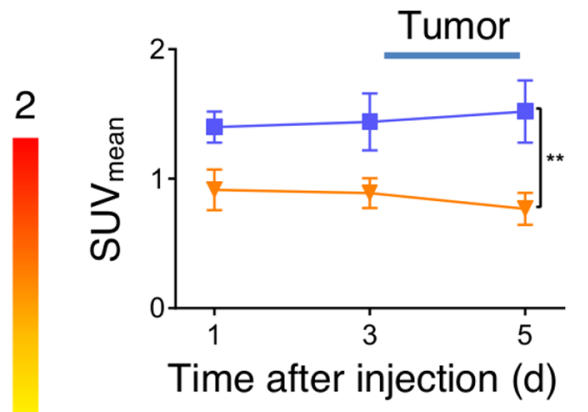

$\stackrel{Q}{<}$

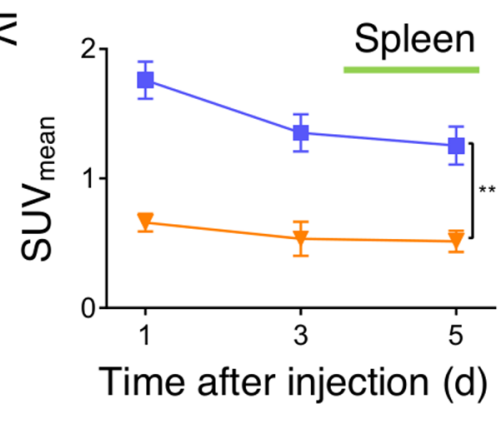

C
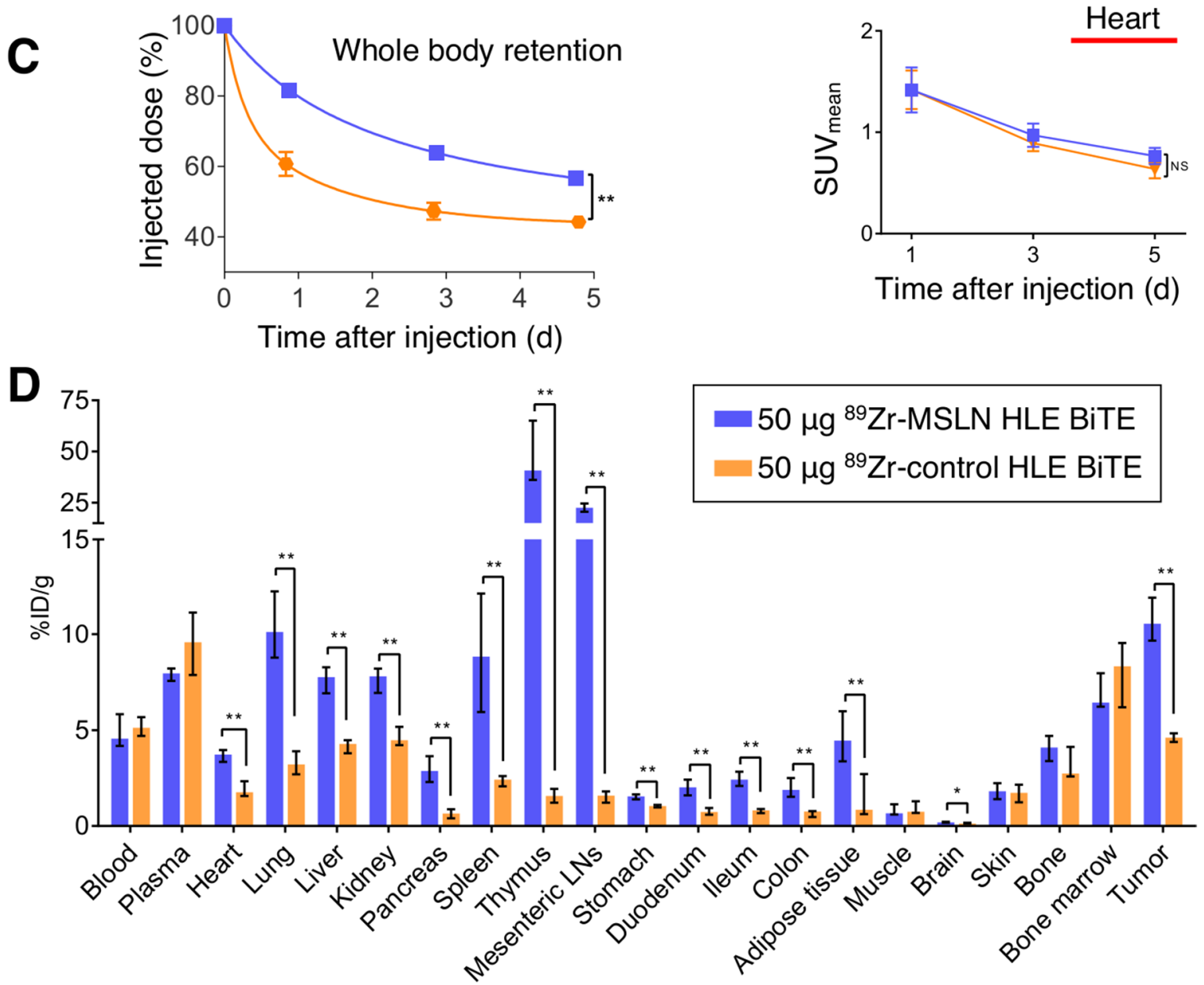
Figure 3. Biodistribution of $50 \mu \mathrm{g}{ }^{89} \mathrm{Zr}-\mathrm{MSLN}$ HLE BiTE compared with $50 \mu \mathrm{g}{ }^{89} \mathrm{Zr}$-control HLE BiTE. A, Representative maximum intensity projections of PET images of 1,3 and 5 days after injection of ${ }^{89} \mathrm{Zr}$-MSLN HLE BiTE $(n=6)$ or ${ }^{89} \mathrm{Zr}$-control HLE BiTE $(n=6)$. Encircled are spleen (green), heart (red) and tumor (blue). B, PET quantification of tumor, spleen and heart. C, Whole-body retention measured by dose calibrator. Data presented as mean \pm standard deviation. D, Ex-vivo biodistribution with data presented as median with interquartile range; ${ }^{*}: P \leq 0.05,{ }^{* *}: P \leq 0.01$. 

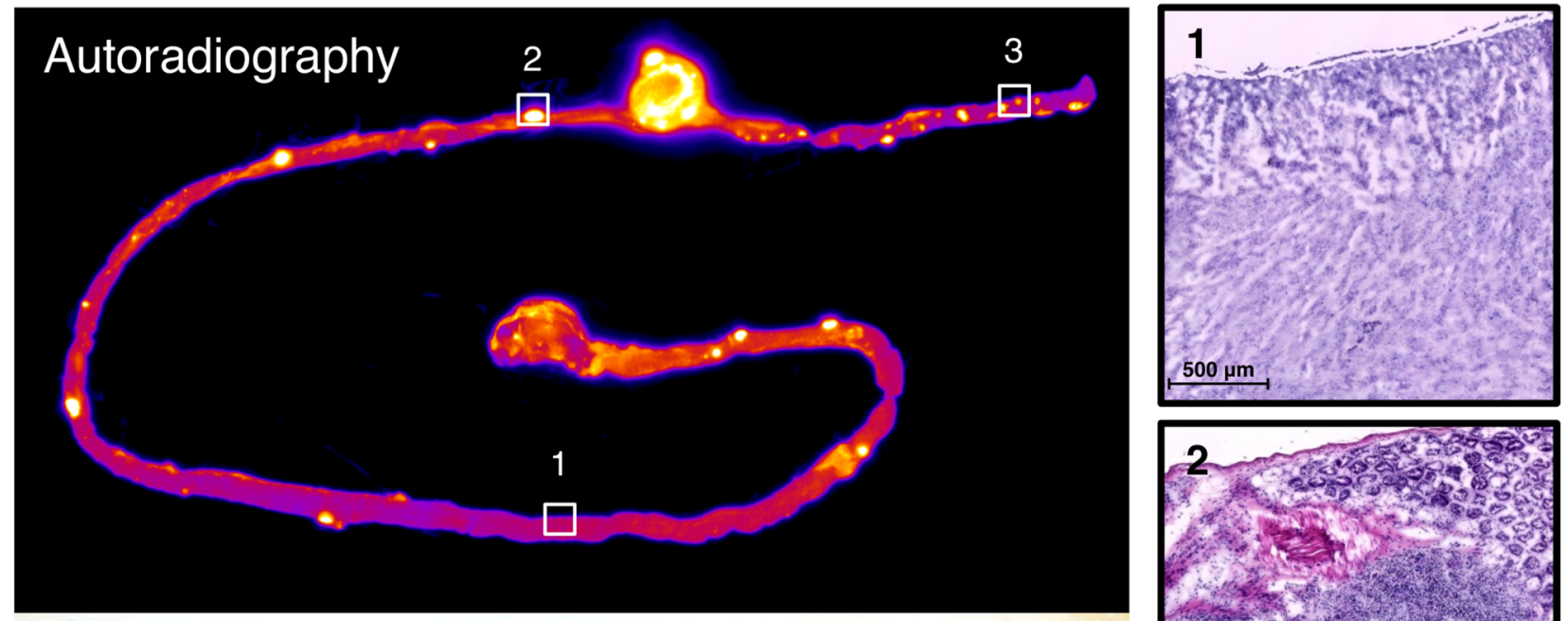

White light

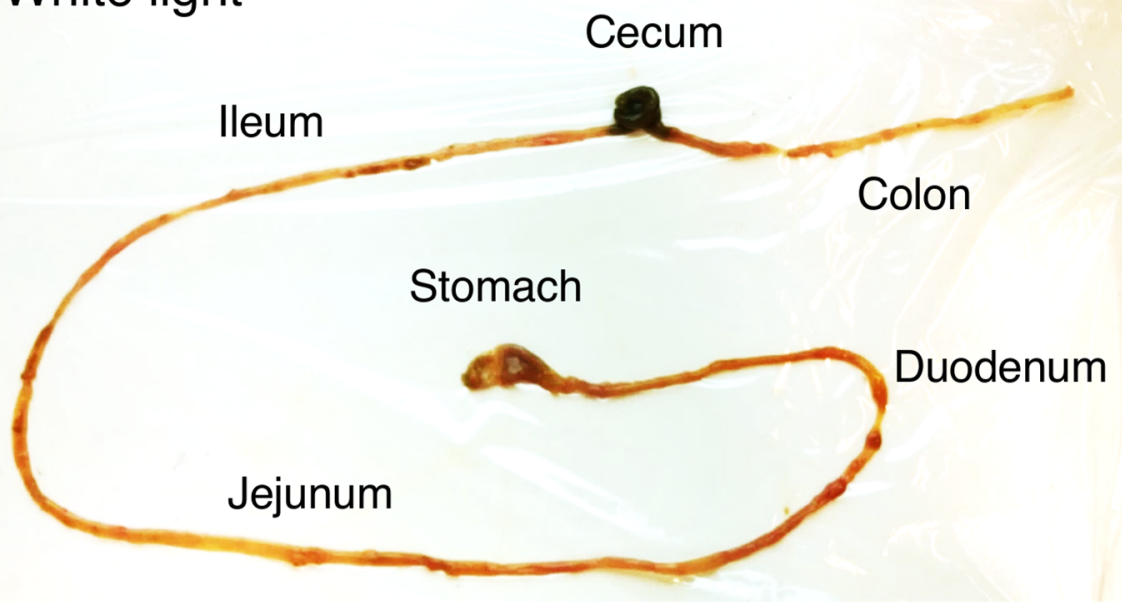

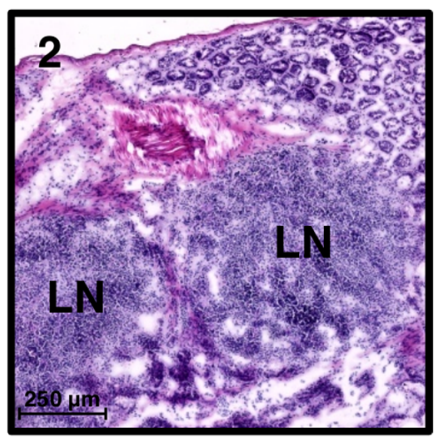

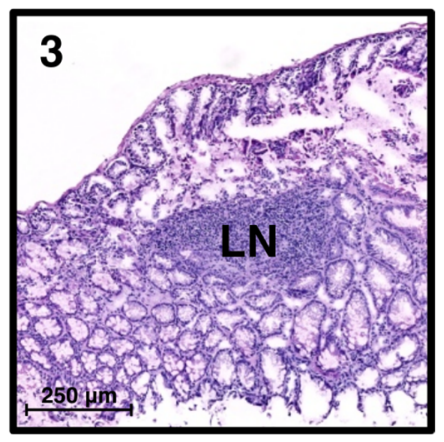

Figure 4. A, Activity retention in the gastrointestinal tract 9 days after injection of $50 \mu \mathrm{g}$ ${ }^{89} \mathrm{Zr}$-MSLN HLE BiTE in a 4T1-tumor bearing BALB/c mouse. Top, autoradiography image. Bottom, corresponding white-light image. B, Hematoxylin and eosin (H\&E) staining of frozen sections of highlighted areas. $L N=$ lymph node. 
A
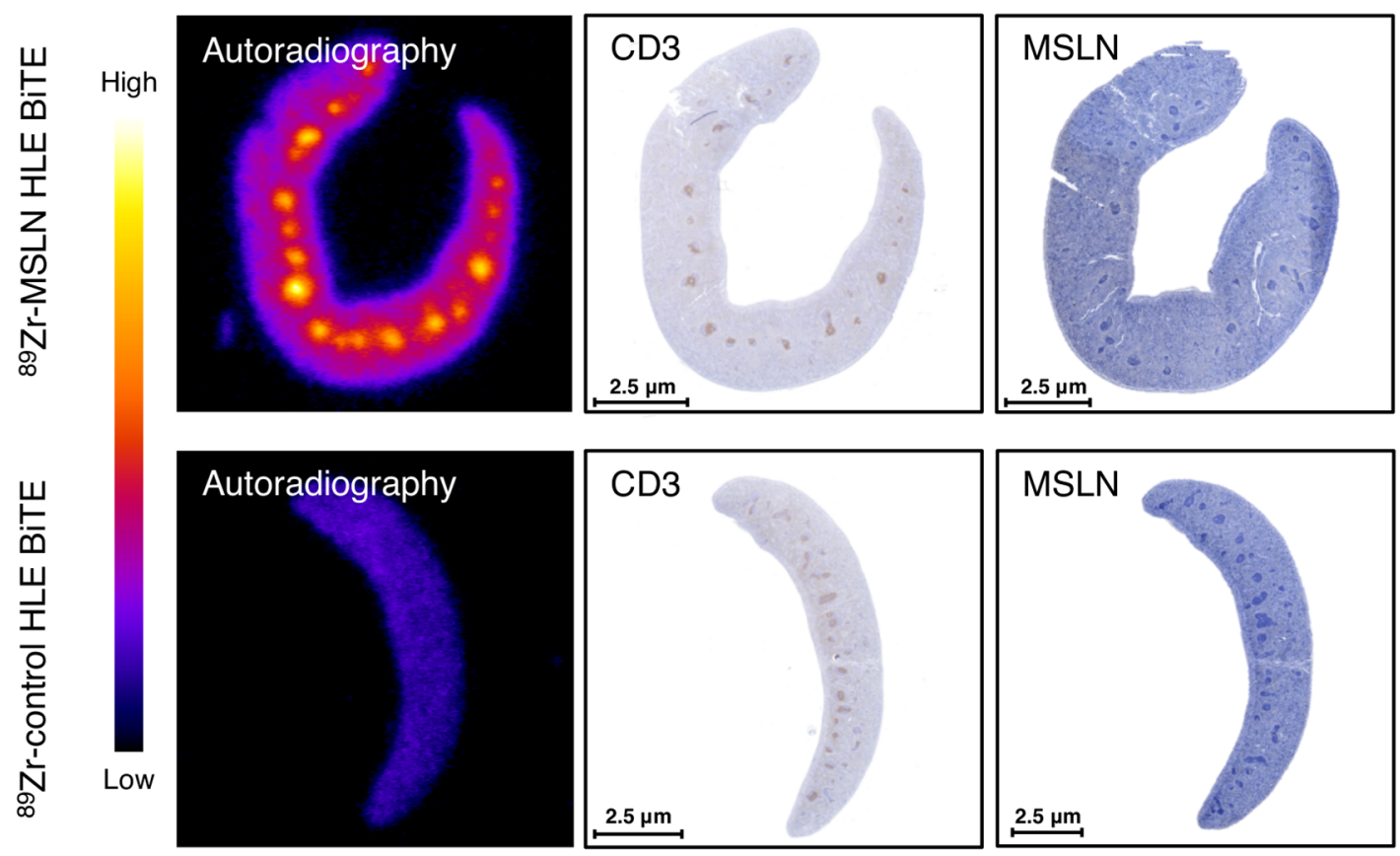

B

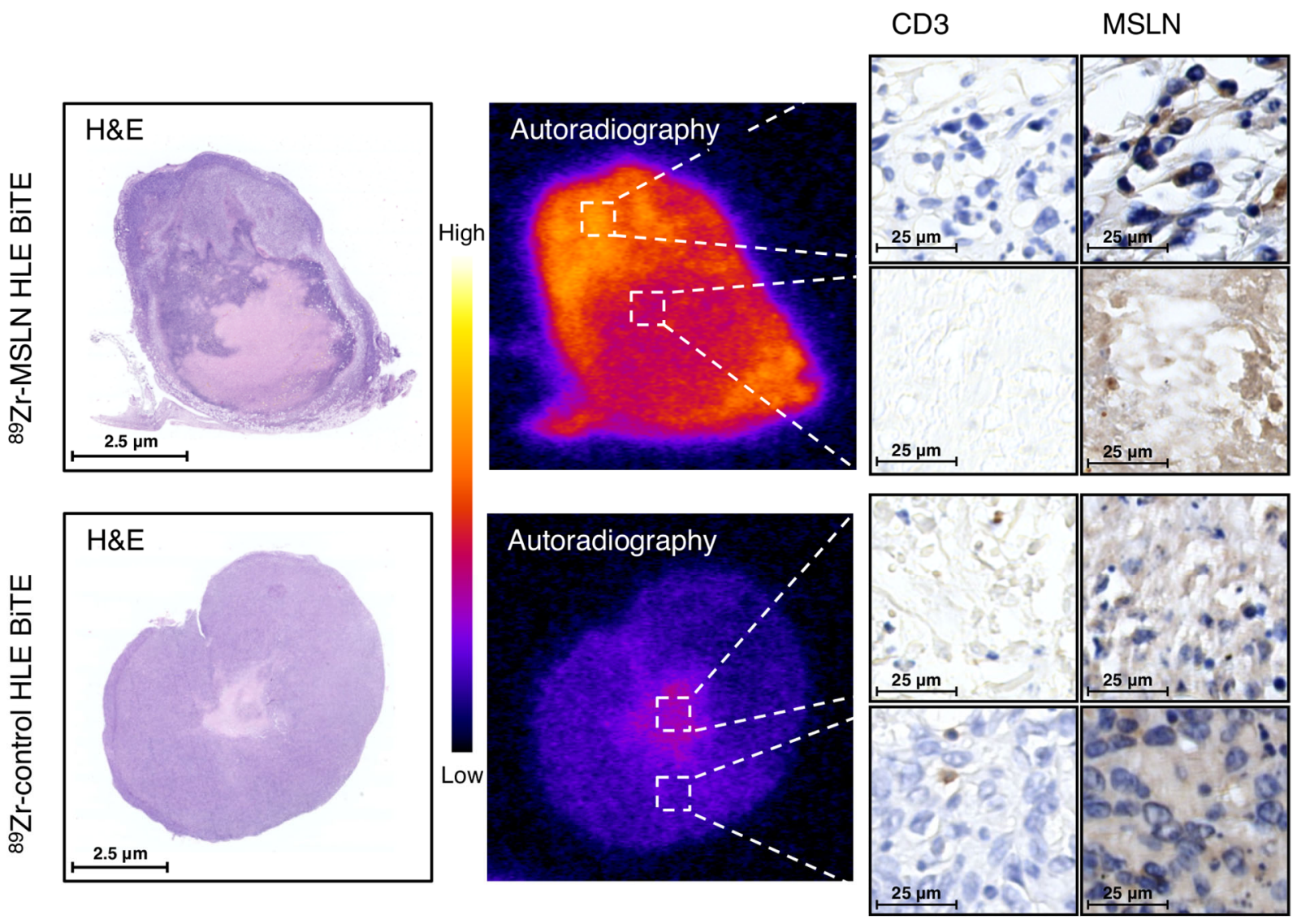


Figure 5. Ex-vivo analysis of spleen and tumor tissue (4T1) 5 days after injection of $50 \mu \mathrm{g}$ ${ }^{89} \mathrm{Zr}$-MSLN HLE BiTE or $50 \mu \mathrm{g}{ }^{89} \mathrm{Zr}$-control HLE BiTE. A, Spleen tissue. From left to right, tissue autoradiography, CD3 immunohistochemistry (IHC) and mesothelin (MSLN) IHC. B, Tumor tissue. From left to right, Hematoxylin and eosin (H\&E), tissue autoradiography, followed by CD3 IHC and MSLN IHC of high and low uptake areas. In the H\&E panel, the necrotic core is shown as a lighter staining region. 


\section{Graphical Abstract}

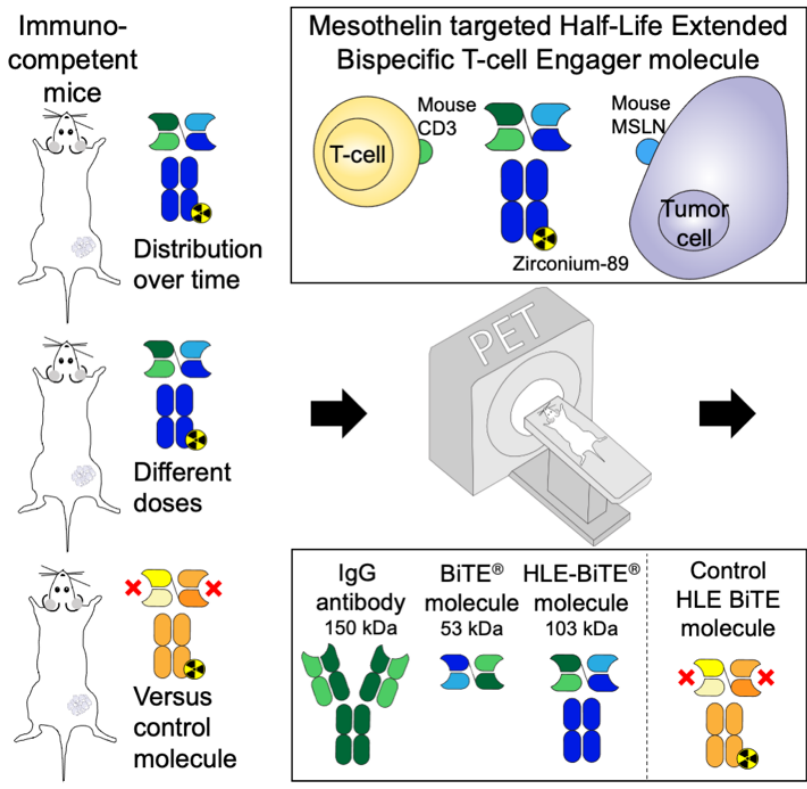

MSLN HLE distributes to both MSLN in tumor and CD3 in lymphoid tissues

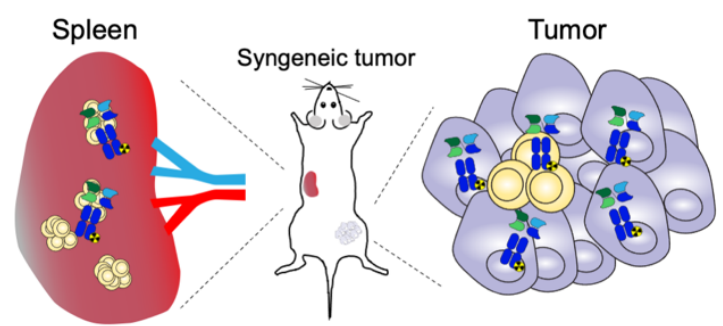

High lymphoid uptake High tumor uptake $t_{1 / 2}=63.4$ hours 


\section{HLE BiTE molecule conjugation, labeling and characterization}

A cell-based assay served to evaluate binding of the MSLN HLE BiTE molecule to its targets. Concentrations from $10^{-3} \mathrm{nM}$ to $10^{3} \mathrm{nM}$ of the MSLN HLE BiTE were incubated for 1 hour at $4{ }^{\circ} \mathrm{C}$ with $2.5 \times 10^{5}$ murine T-cells or $4 \mathrm{~T} 1$ cells. Murine T-cells were obtained by negative selection with the Pan T-Cell Isolation Kit II, mouse (Miltenyi Biotec). After incubation for 1 hour at $4{ }^{\circ} \mathrm{C}$ with the MSLN HLE BiTE, cells were washed and incubated with a secondary antibody, either goat anti-mouse IgG-APC (Jackson ImmunoReseach) or goat anti-mouse IgG - AF647 (Invitrogen). Cells were gated for live cells with fixable viability dye eFluor 506 (Affymetrix, eBioscience). Data was acquired by BD LSRFortessa Flow Cytometer (BD Biosciences) and analyzed with FlowJo software (FlowJo v10). Mesothelin expression was quantified on 4T1 and OVCAR8 cells with a standard receptor quantitation QIFIKIT® assay (Dako).

Specific cytotoxicity of MSLN HLE BiTE and the control HLE BiTE molecule was studied adding concentrations of $10^{-3} \mathrm{pM}$ to $10^{4} \mathrm{pM}$ of either molecule to mouse T-cells and $10^{4} 4 \mathrm{~T} 1$ or B16F10 tumor cells in a ratio of $10: 1$. The melanoma cell line B16F10 (ATCC) was cultured in DMEM medium (Biochrom) containing 10\% fetal calf serum (Invitrogen). Read-outs were propidium iodide-positive tumor cells for cytotoxicity and CD69-positive T-cells for T-cell activation. Data was acquired by FACS Canto II (BD Biosciences) and sigmoidal curves were generated using GraphPad Prism 7.

Both HLE BiTE molecules were conjugated as previously described (13). In short, tetrafluorophenol- $N$-succinyl-desferrioxamine-Fe (TFP- $N$-suc-DFO-Fe; $\quad$ ABX) was conjugated to the MSLN HLE BiTE and the control HLE BiTE. Conjugation efficiency and protein purity were evaluated by size exclusion ultra-performance liquid chromatography (SE-UPLC, Waters) with a dual-wavelength absorbance detector (280 $\mathrm{nm}$ versus 430 
$1 \mathrm{~nm}$ ). A TSKgel G3000SWxL column (Tosoh) and phosphate-buffered saline (140 mmol/L

$2 \mathrm{NaCl}, 9 \mathrm{mmol} / \mathrm{L} \mathrm{Na} 2 \mathrm{HPO}_{4}, 1.3 \mathrm{mmol} / \mathrm{L} \mathrm{NaH}_{2} \mathrm{PO}_{4} ; \mathrm{pH}$ 7.4) as mobile phase were used. The

3 conjugate with a concentration of $1 \mathrm{mg} / \mathrm{mL}$ was stored at $-80{ }^{\circ} \mathrm{C}$. Stability by assessing

4 the formation of low and high molecular weight species was determined by SE-UPLC

5 analysis. Maintained immunoreactivity for both arms was studied by functional cell-based

6 assays: cytotoxicity and T-cell activation. Concentrations of $10^{-3} \mathrm{ng} / \mathrm{mL}$ to $10^{3} \mathrm{ng} / \mathrm{mL}$

7 conjugated or unmodified HLE BiTE molecules were added to murine T-cells and $10^{4} 4 \mathrm{~T} 1$

8 tumor cells in a ratio of 10:1. Read-outs were propidium iodide-positive tumor cells for

9 cytotoxicity and CD69-positive T-cells for T-cell activation. Data was acquired by FACS

10 Canto II.

11 The conjugated HLE BiTE molecules were labeled with ${ }^{89} \mathrm{Zr}$, as described

12 previously (25). Radiochemical purity was evaluated by a trichloroacetic acid precipitation

13 assay and SE-UPLC analysis. No visible particles were detected. Conjugated MSLN HLE

14 BiTE and conjugated control HLE BiTE were labeled with ${ }^{89} \mathrm{Zr}$ with $>95 \%$ radiochemical

15 purity at a specific activity of $400-500 \mathrm{MBq} / \mathrm{mg}$.

16 A radiolabeled protein dose of $10 \mu \mathrm{g}{ }^{89} \mathrm{Zr}$-MSLN HLE BiTE or $10 \mu \mathrm{g}{ }^{89} \mathrm{Zr}$-control

17 HLE BiTE was prepared for each dose group. A cold protein dose of the respective

18 unlabeled parental HLE BiTE was added to the hot dose to reach a final protein dose of

$1950 \mu \mathrm{g}$ or $200 \mu \mathrm{g}$.

20 
A

\section{B}

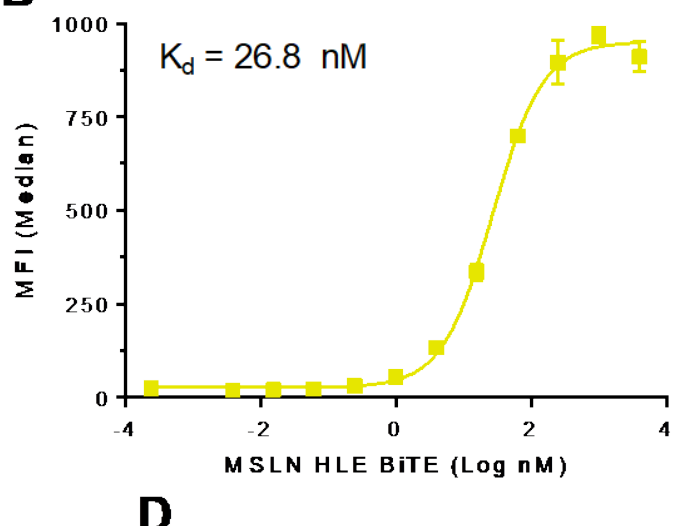

D

F
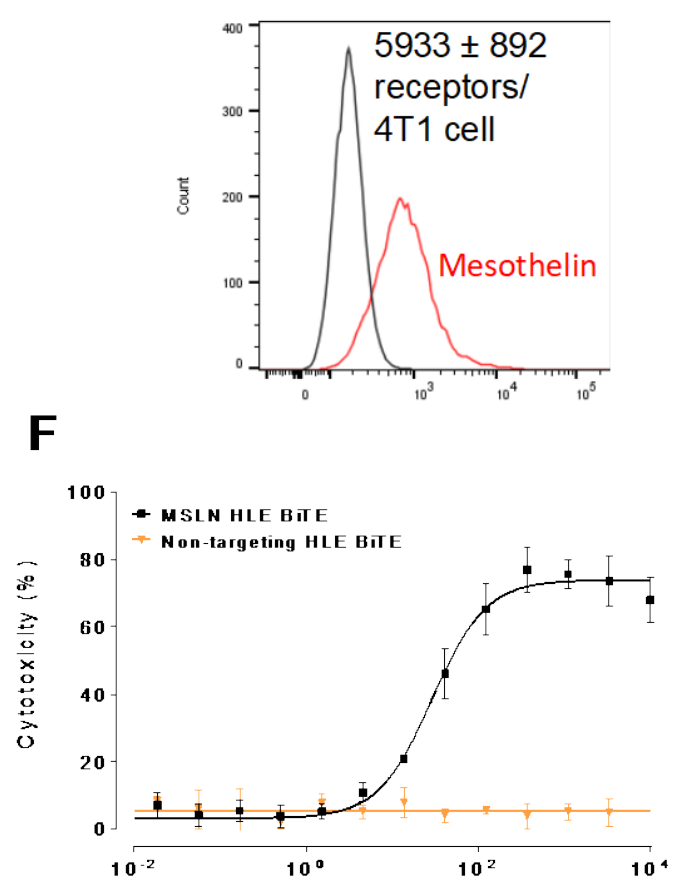

1

molecule

$53 \mathrm{kDa}$

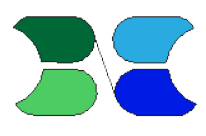

BiTE HLE BiTE

C

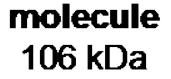

106 kDa
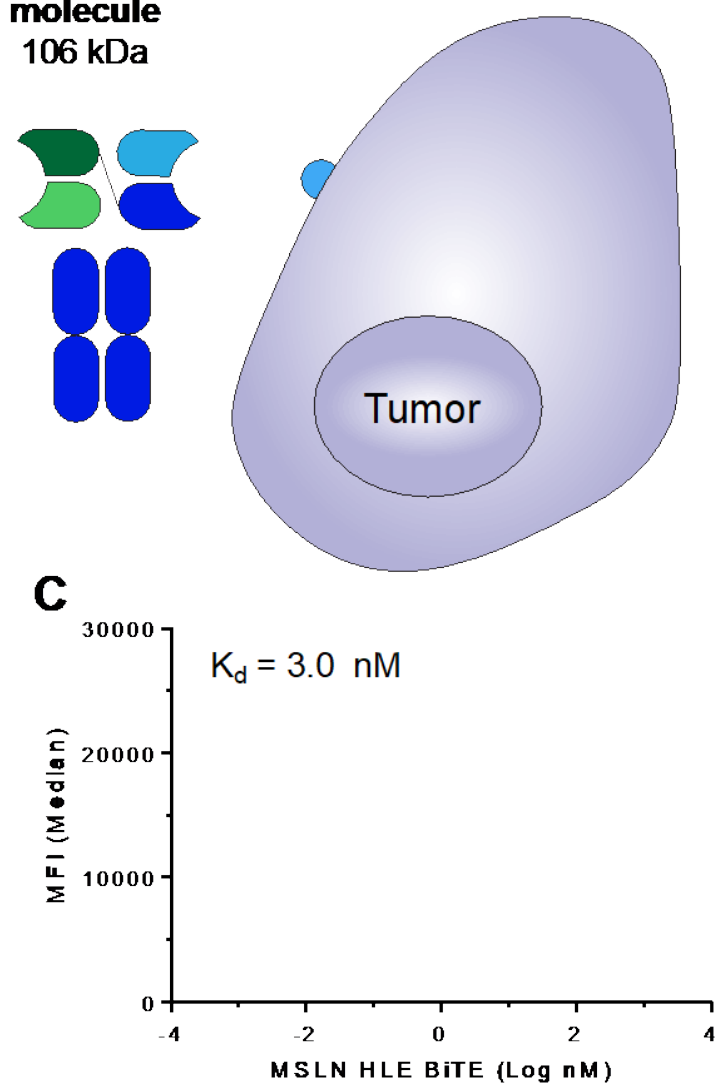

E

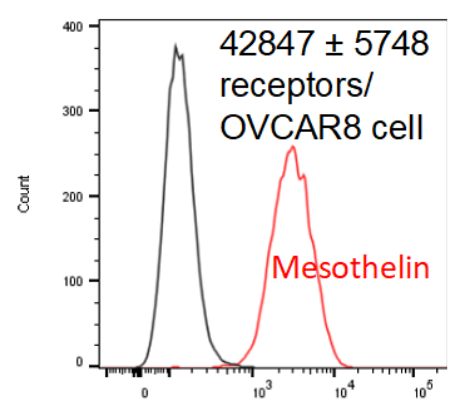

G

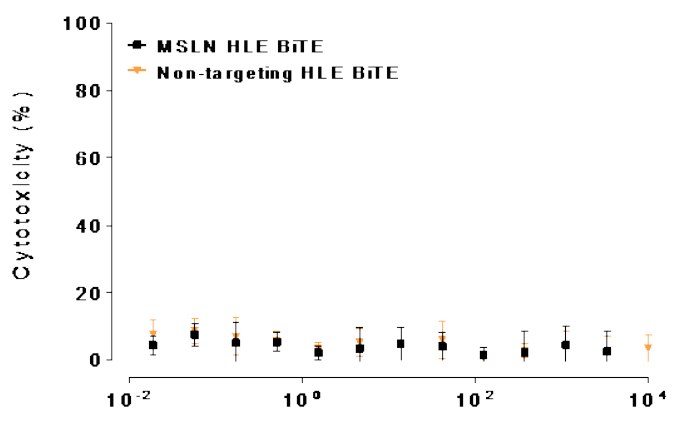

HLE BiTE molecule ( $p M$ ) 
1 Supplementary Figure 1. A, Simplified schematic overview of a canonical BiTE and HLE

2 BiTE molecule. Both bind to T-cell and tumor, but the HLE BiTE has an Fc-domain

3 increasing its size. B, Binding assay of the MSLN HLE BiTE with CD3 on murine T-cells.

4 C, Binding assay of the MSLN HLE BiTE with mesothelin on 4T1 cells. Data is presented

5 as mean \pm standard deviation. D and E, Mesothelin expression (red) on 4T1 cells (D) and

6 on OVCAR8 cells $(E)$ expressed as mean \pm standard deviation $(n=2) . F$ and $G$,

7 cytotoxicity assay with T-cells: 4T1-tumor cells (F) and B16F10 (G, mesothelin negative)

8 incubated at a ratio of $10: 1$. 
A

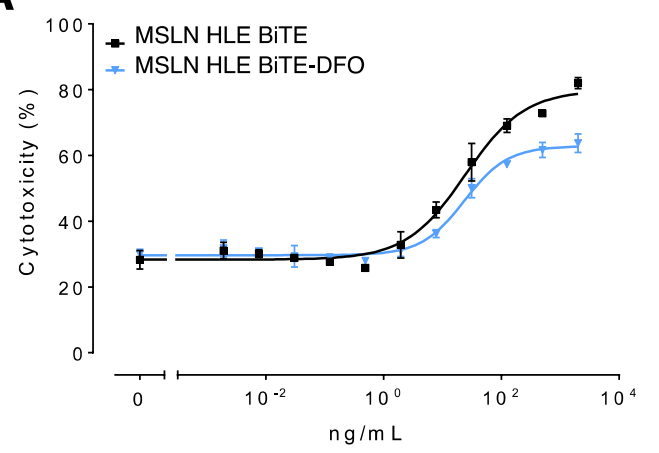

B

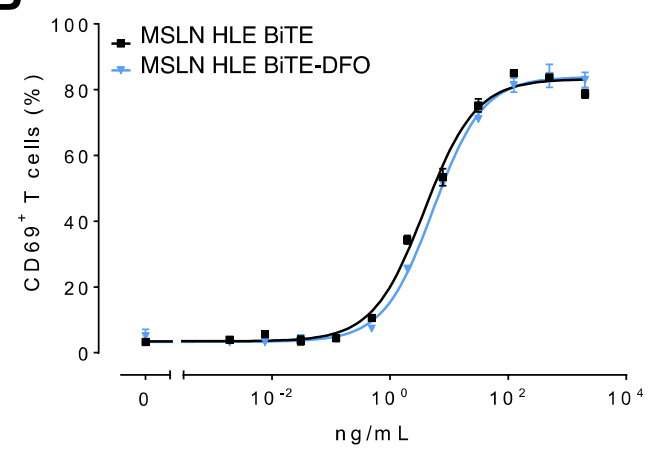

C

\begin{tabular}{ccc}
\hline HLE BiTE Construct & $\begin{array}{c}\text { Cytotoxicity } \\
\mathrm{EC}_{50}(\mathrm{ng} / \mathrm{mL})\end{array}$ & $\begin{array}{c}\text { CD69 activation } \\
\mathrm{EC}_{50}(\mathrm{ng} / \mathrm{mL})\end{array}$ \\
\hline MSLN HLE BiTE & 24.3 & 3.82 \\
MSLN HLE BiTE-DFO & 23.6 & 5.40 \\
\hline
\end{tabular}

D
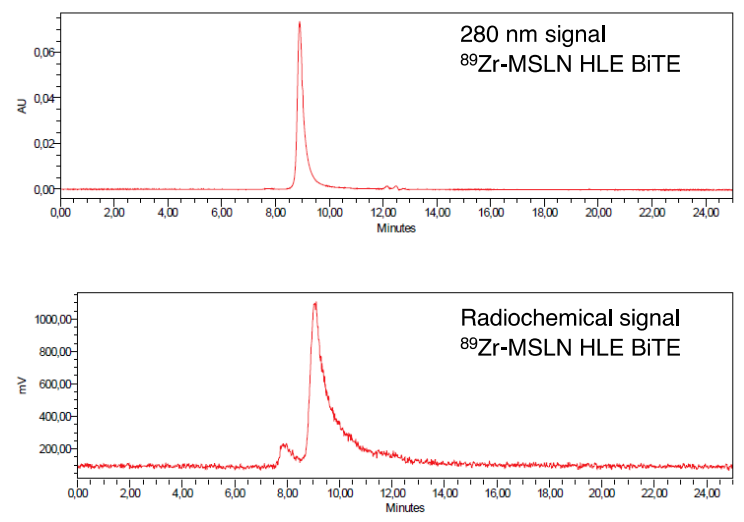

E
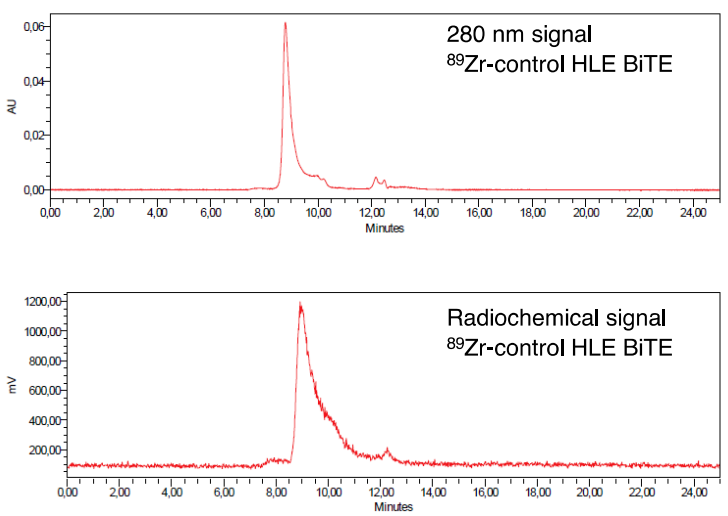

2 Supplementary Figure 2. Characterization of ${ }^{89} \mathrm{Zr}$-HLE BiTE. Functionality assessed by

3 cell-based assays with T-cells: 4T1-tumor cells incubated at a ratio of 10:1. A, Cytotoxicity assay. B, T-cell activation by CD69 expression. Data is presented as mean \pm standard

5 deviation. C, Quantification of sigmoidal curves of A and B. D, UPLC protein signal (280

$6 \mathrm{~nm}$ ) and radiochemical signal of ${ }^{89} \mathrm{Zr}$-MSLN HLE BiTE. E, UPLC protein signal ( $280 \mathrm{~nm}$ )

7 and radiochemical signal of ${ }^{89} \mathrm{Zr}$-control HLE BiTE. 

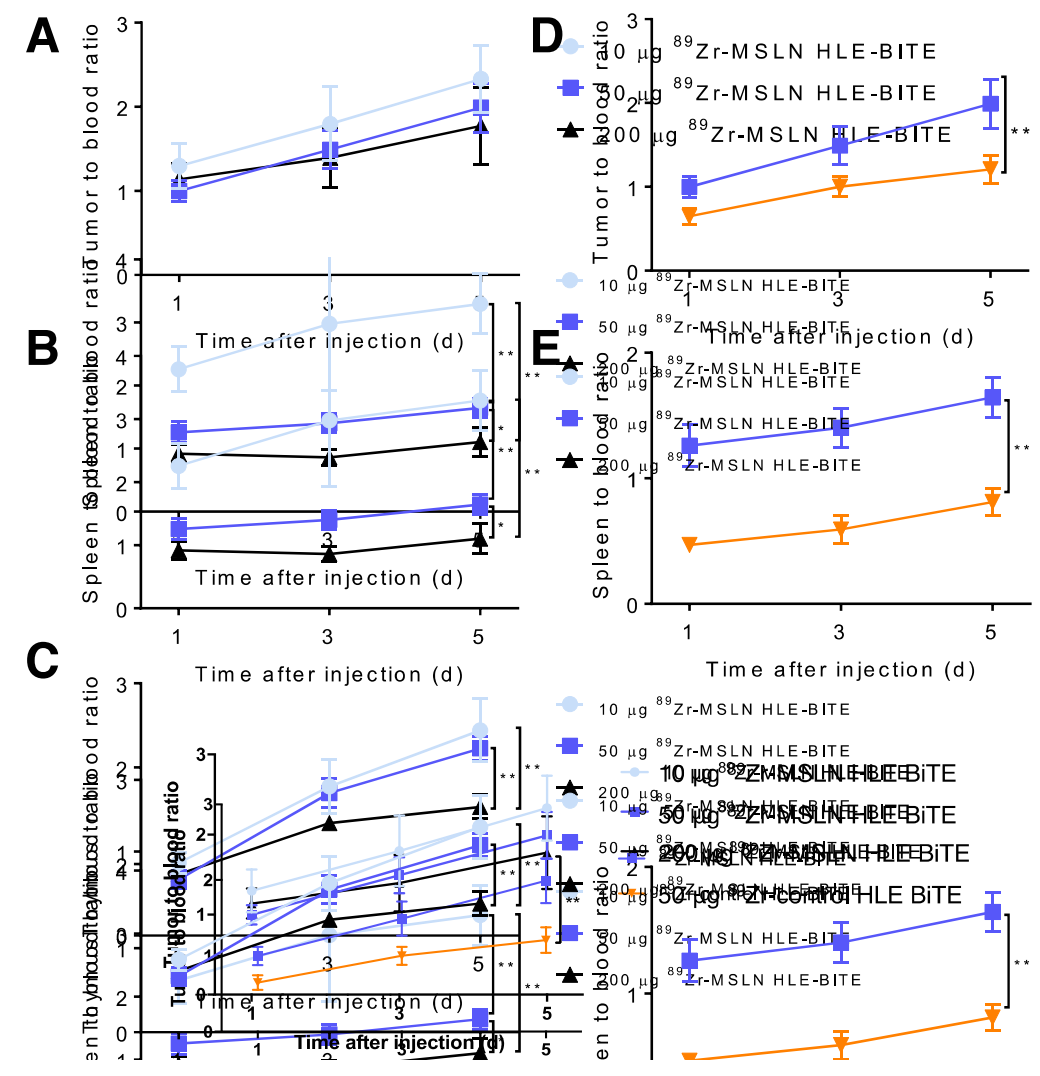

2 Supplementary Figure 3. Organ-to-blood ratios of 10, 50 or $200 \mu g$ 89 Zr-MSLN HLE A,

3 Tumor. B, Spleen. C, Thymus. Organ-to-blood ratios of $50 \mu g{ }^{89} \mathrm{Zr}$-MSLN HLE BiTE

4 compared with $50 \mu \mathrm{g}{ }^{89} \mathrm{Zr}$-control HLE BiTE D, Tumor. E, Spleen. 
A

$10 \mu \mathrm{g}$
${ }^{89} \mathrm{Zr}-\mathrm{MSLN}$

HLE BTE

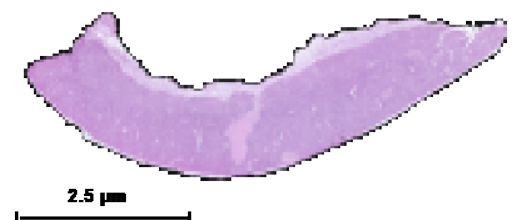

$50 \mu \mathrm{g}$

${ }^{89} \mathrm{Zr}$-MSLN

HLE BTE

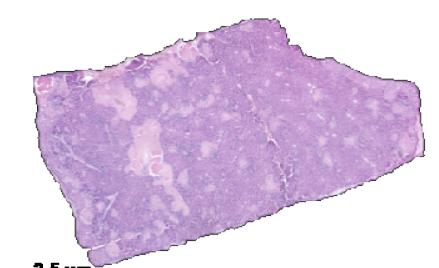

$25 \mu$

$200 \mu \mathrm{g}$

${ }^{89}$ Zr-MSLN

HLE BTE

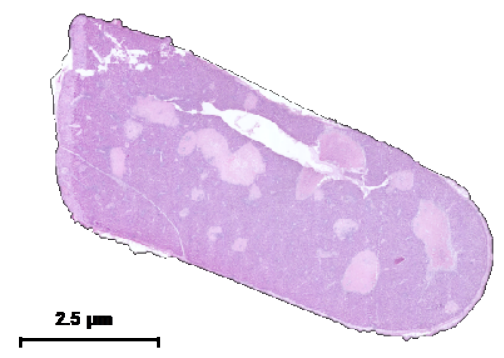

$50 \mu \mathrm{g}$

${ }^{89} \mathrm{Zr}$-control HLE BTE
B

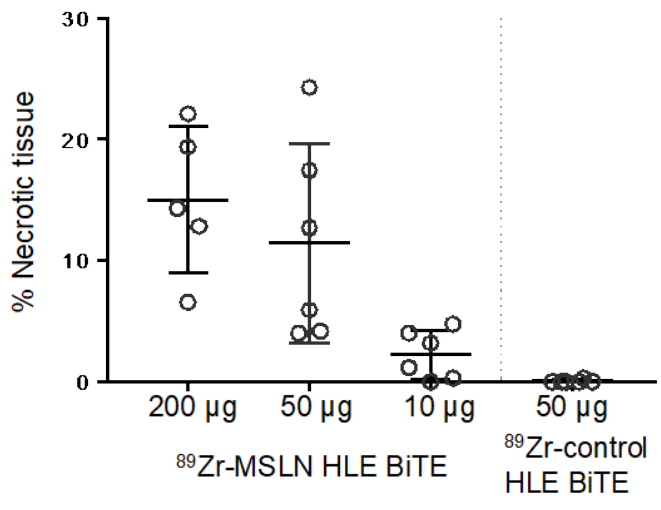

C

\begin{tabular}{cc}
\hline Solution & $\begin{array}{c}\text { Endotoxin } \\
\text { (EU/mL) }\end{array}$ \\
\hline MSLN HLE BiTE stock & 0.532 \\
$\begin{array}{c}\text { MSLN HLE BiTE-N-suc-DFO } \\
\text { stock }\end{array}$ & 0.737 \\
$\begin{array}{c}\text { Injection 200 } \text {. }^{89} \text { Zr-MSLN } \\
\text { HLE BiTE }\end{array}$ & 0.405 \\
\hline
\end{tabular}

2 Supplementary Figure 4. Analysis of the liver of 4T1-tumor bearing mice. A,

3 Representative H\&E stainings from the different tracer dose groups. B, Necrotic area of

4 liver tissue expressed as a percentage of the area of the entire H\&E stained slice. Data is

5 presented as mean \pm standard deviation. C, Endotoxin values measured by a limulus

6 amebocyte lysate assay. 


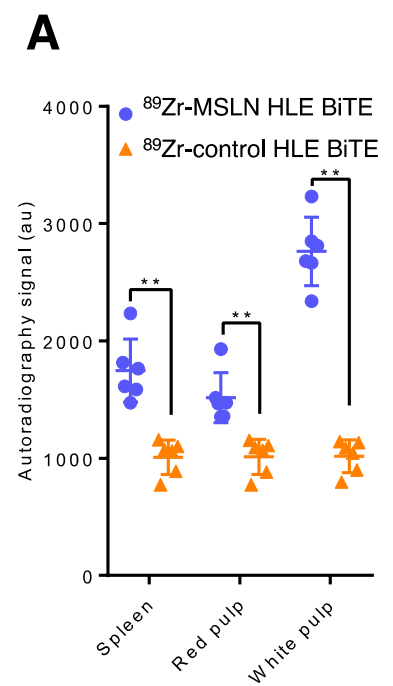

1

2 Supplementary Figure 5. Red and white pulp quantified from autoradiography data from

3 Figure 5A, normalized for injected activity. Data expressed as arbitrary units (au)

4 presented as mean \pm standard deviation; *: $P \leq 0.05,{ }^{* *}: P \leq 0.01$. 
${ }^{89} \mathrm{Zr}$-MSLN HLE BiTE
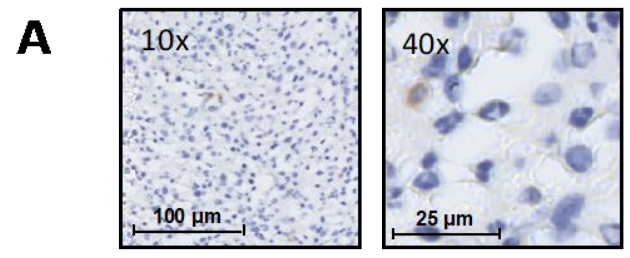

\section{CD3 IHC}
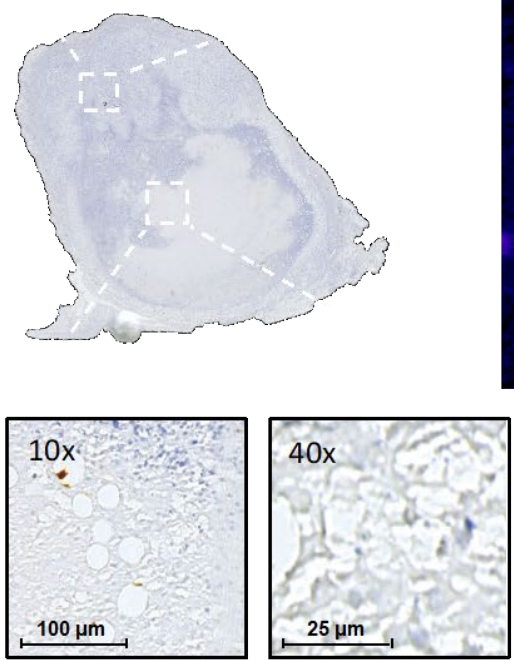

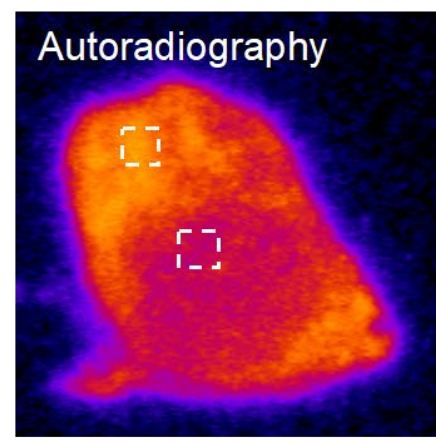

MSLN IHC
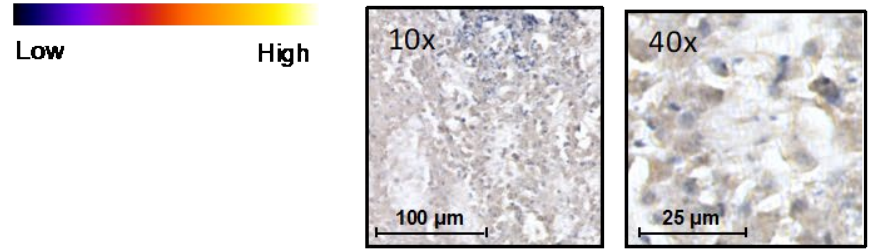

B

${ }^{89}$ Zr-control HLE BiTE
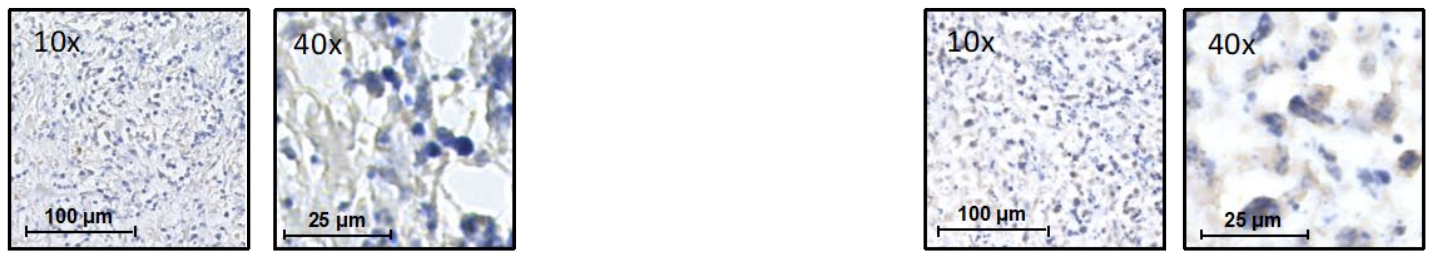

CD3 IHC
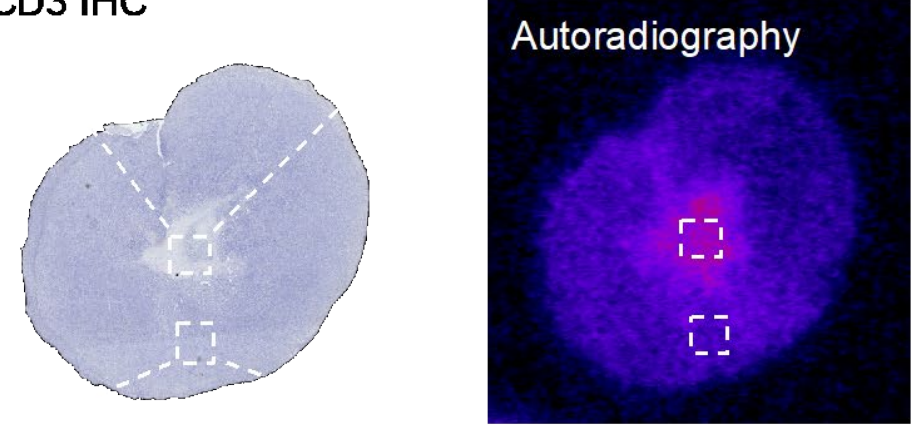

MSLN IHC
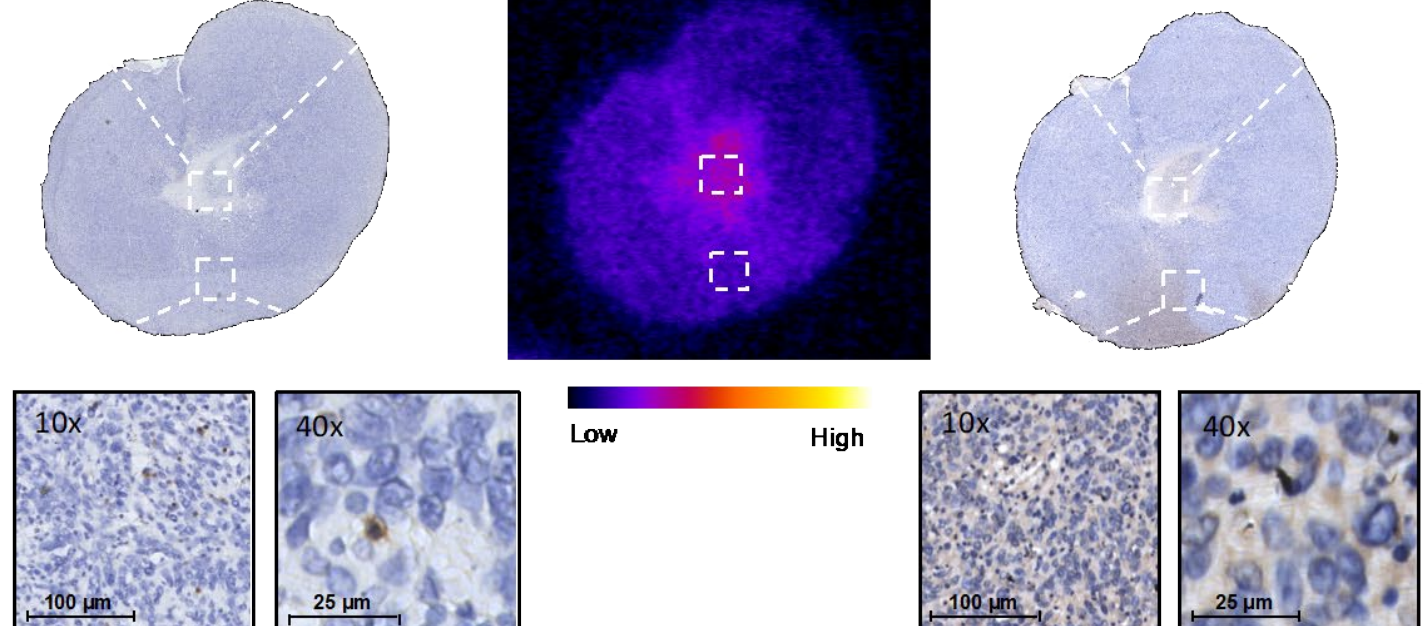
1 Supplementary Figure 6. Magnifications from Figure 5A and Figure 5B, Ex vivo analysis

2 of spleen and tumor tissue (4T1) 5 days after injection of $50 \mu \mathrm{g}{ }^{89} \mathrm{Zr}-\mathrm{MSLN}$ HLE BiTE or $350 \mu \mathrm{g}{ }^{89} \mathrm{Zr}$-control HLE BiTE. Left side, CD3 IHC. Right side, Mesothelin IHC. 
A

1

$$
H \& E
$$

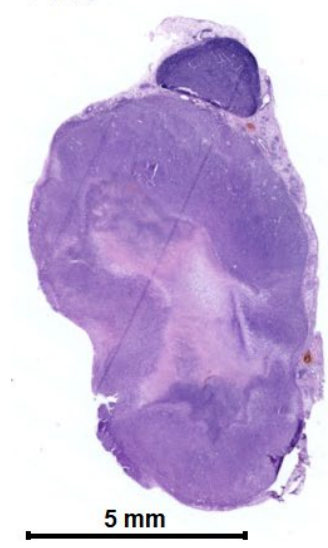

Autoradiography

High

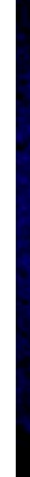

Low

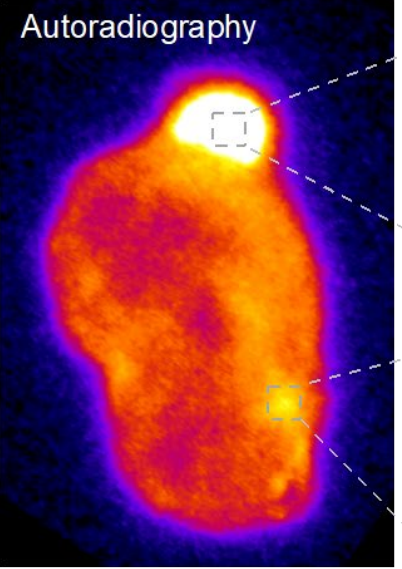

Lymph node

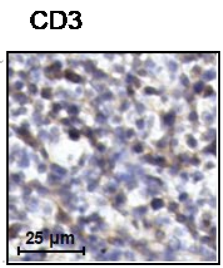

Hotspot

CD3

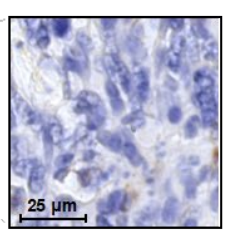

B

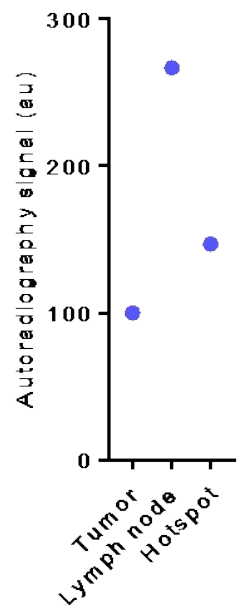

2 Supplementary Figure 7. Ex vivo microscopic analysis of tumor tissue with adjacent

3 lymph node 5 days after injection of $50 \mu \mathrm{g}{ }^{89} \mathrm{Zr}-\mathrm{MSLN}$ HLE BiTE. A, From left to right,

4 hematoxylin and eosin (H\&E) staining and corresponding autoradiography. Next,

5 immunohistochemistry (IHC) on CD3 and mesothelin (MSLN) expression. B, Quantified

6 autoradiography data showing higher signal in regions of interest in lymph node than in

7 the tumor and tumor hotspot. Data expressed as arbitrary units (au). 
1 Supplementary Table 1. Ex vivo biodistribution data of the three dose groups 5 days

2 after ${ }^{89} \mathrm{Zr}$-MSNL HLE BiTE tracer injection in 4T1-tumor bearing syngeneic mice.

\begin{tabular}{|c|c|c|c|c|}
\hline Tissue & 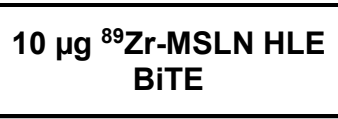 & $\begin{array}{c}50 \mu g{ }^{89} \mathrm{Zr}-\mathrm{MSLN} \text { HLE } \\
\text { BiTE }\end{array}$ & $\begin{array}{c}200 \mu g{ }^{89} \mathrm{Zr}-\mathrm{MSLN} \text { HLE } \\
\text { BiTE }\end{array}$ & $\begin{array}{l}\text { ANOVAI } \\
\text { Kruskal- } \\
\text { Wallis } P\end{array}$ \\
\hline Blood & 2.72 (2.49 to 4.12 ) & 4.56 (4.17 to 5.83$)$ & 5.51 (4.66 to 6.06$)$ & 0.013 \\
\hline Plasma & $4.68(4.68$ to 5,18$)$ & $7.96(7.56$ to 8.21$)$ & $10.13(8.55$ to 12.05$)$ & $<0.001$ \\
\hline Heart & 2.25 (2.07 to 2.50$)$ & 3.73 (3.34 to 3.96$)$ & 2.59 (2.40 to 2.95$)$ & $<0.001$ \\
\hline Lung & 7.47 (4.90 to 9.31$)$ & 10.11 (8.78 to 12.28$)$ & 7.35 (5.43 to 8.31$)$ & 0.030 \\
\hline Liver & $9.16(8.06$ to 9.45$)$ & 7.77 (6.92 to 8.28$)$ & $5.92(4.62$ to 7.86$)$ & 0.005 \\
\hline Kidney & $6.94(6.52$ to 7.11$)$ & $7.80(6.94$ to 8.21$)$ & 7.09 (6.28 to 7.69$)$ & ns \\
\hline Pancreas & 2.58 (1.81 to 2.93 ) & 2.88 (2.30 to 3.65$)$ & 2.35 (1.92 to 2.59$)$ & ns \\
\hline Spleen & $10.12(9.53$ to 12.71$)$ & 8.83 (5.95 to 12.17$)$ & 4.46 (3.85 to 6.75$)$ & 0.003 \\
\hline Thymus & 28.95 (19.88 to 34.20$)$ & 40.78 (36.15 to 65.11$)$ & $28.49(17.97$ to 49.90$)$ & ns \\
\hline Mesenteric LNs & 31.97 (21.16 to 39.89$)$ & 22.57 (20.58 to 24.67$)$ & $12.03(10.30$ to 12.67$)$ & $<0.001$ \\
\hline Stomach & $1.39(0.91$ to 1.65$)$ & $1.55(1.44$ to 1.64$)$ & $1.65(1.25$ to 1.84$)$ & ns \\
\hline Duodenum & $1.42(0.82$ to 1.99$)$ & 2.02 (1.59 to 2.42 ) & 1.55 (1.29 to 2.03$)$ & ns \\
\hline lleum & 2.11 (2.06 to 2.49$)$ & 2.42 (2.09 to 2.83$)$ & 1.64 (1.32 to 2.52$)$ & ns \\
\hline Colon & 1.38 (1.18 to 1.49$)$ & 1.88 (1.53 to 2.50$)$ & $1.56(1.23$ to 1.68$)$ & ns \\
\hline Adipose tissue & 4.36 (2.87 to 5.56$)$ & 4.46 (3.37 to 5.98$)$ & $3.10(2.05$ to 4.35$)$ & ns \\
\hline Muscle & $0.40(0.30$ to 0.65$)$ & $0.66(0.60$ to 1.13$)$ & $0.67(0.58$ to 1.41$)$ & 0.032 \\
\hline Brain & $0.15(0.13$ to 0.17$)$ & $0.19(0.17$ to 0.23$)$ & $0.26(0.22$ to 0.39$)$ & $<0.001$ \\
\hline Skin & $1.40(0.67$ to 2.04$)$ & 1.81 (1.40 to 2.23$)$ & 1.65 (1.40 to 2.78$)$ & ns \\
\hline Bone & $5.00(4.22$ to 6.62$)$ & 4.09 (3.39 to 4.70$)$ & 3.75 (3.33 to 4.67$)$ & ns \\
\hline Bone marrow & 5.25 (4.25 to 6.05$)$ & $6.44(6.22$ to 7.96$)$ & $8.16(7.79$ to 9.43$)$ & ns \\
\hline Tumor & $8.76(8.31$ to 12.31$)$ & 10.59 (9.66 to 11.95$)$ & 9.52 (9.28 to 9.96$)$ & ns \\
\hline
\end{tabular}

3

4 Data is presented as median $\% \mathrm{ID} / \mathrm{g}$ values with interquartile range from $10 \mu \mathrm{g}{ }^{89} \mathrm{Zr}-\mathrm{MSLN}$

5 HLE BiTE $(n=6), 50 \mu g$ 89Zr-MSLN HLE BiTE $(n=6)$ and $200 \mu g$ 89Zr-MSLN HLE BiTE $6(\mathrm{n}=5)$. An analysis of variance was performed with the Kruskal-Wallis test, $P$-values < $7 \quad 0.05$ are shown. $\mathrm{LN}=$ lymph node, $\mathrm{ns}=$ non-significant. 
1 Supplementary Table 2. Ex vivo biodistribution data of $50 \mu \mathrm{g}{ }^{89} \mathrm{Zr}-\mathrm{MSLN}$ HLE BiTE $(\mathrm{n}=$ $26)$ and $50 \mu \mathrm{g}{ }^{89} \mathrm{Zr}$-control HLE BiTE $(\mathrm{n}=6) 5$ days after tracer injection in 4T1-tumor 3 bearing syngeneic mice.

\begin{tabular}{|c|c|c|c|}
\hline Tissue & $\begin{array}{c}50 \mu \mathrm{g}{ }^{89} \mathrm{Zr}-\mathrm{MSLN} \text { HLE } \\
\text { BiTE }\end{array}$ & $\begin{array}{c}50 \mu g^{89} \mathrm{Zr} \text {-control } \\
\text { HLE BiTE }\end{array}$ & $\begin{array}{c}\text { Mann- } \\
\text { Whitney } P\end{array}$ \\
\hline Blood & 4.56 (4.17 to 5.83$)$ & 5.33 (4.78 to 6.06 ) & ns \\
\hline Plasma & 7.96 (7.56 to 8.21$)$ & 10.30 (7.89 to 11.80$)$ & ns \\
\hline Heart & 3.73 (3.34 to 3.96 ) & 1.81 (1.58 to 2.51$)$ & 0.002 \\
\hline Lung & 10.11 (8.78 to 12.28 ) & 3.24 (2.74 to 4.48$)$ & 0.002 \\
\hline Liver & 7.77 (6.92 to 8.28$)$ & 4.40 (3.94 to 4.65$)$ & 0.002 \\
\hline Kidney & 7.80 (6.94 to 8.21$)$ & 4.62 (4.27 to 6.10$)$ & 0.004 \\
\hline Pancreas & 2.88 (2.30 to 3.65 ) & $0.71(0.41$ to 1.19$)$ & 0.002 \\
\hline Spleen & 8.83 (5.95 to 12.17$)$ & 2.47 (2.15 to 2.62$)$ & 0.002 \\
\hline Thymus & 40.78 (36.15 to 65.11$)$ & 1.68 (1.30 to 2.15$)$ & 0.002 \\
\hline Mesenteric LNs & 22.57 (20.58 to 24.67 ) & 1.66 (1.29 to 1.82$)$ & 0.002 \\
\hline Stomach & 1.55 (1.44 to 1.64$)$ & $1.05(0.97$ to 1.21$)$ & 0.002 \\
\hline Duodenum & 2.02 (1.59 to 2.42 ) & $0.83(0.64$ to 0.98$)$ & 0.002 \\
\hline Ileum & 2.42 (2.09 to 2.83 ) & $0.86(0.70$ to 0.94$)$ & 0.002 \\
\hline Colon & 1.88 (1.53 to 2.50$)$ & 0.76 (0.48 to 0.79$)$ & 0.002 \\
\hline Adipose tissue & 4.46 (3.37 to 5.98$)$ & $0.86(0.65$ to 3.13$)$ & 0.002 \\
\hline Muscle & 0.66 (0.60 to 1.13$)$ & 0.75 (0.70 to 1.41$)$ & ns \\
\hline Brain & 0.19 (0.17 to 0.23$)$ & $0.13(0.13$ to 0.19$)$ & 0.015 \\
\hline Skin & 1.81 (1.40 to 2.23 ) & 2.01 (1.29 to 2.17$)$ & ns \\
\hline Bone & 4.09 (3.39 to 4.70$)$ & 2.78 (2.60 to 4.21$)$ & ns \\
\hline Bone marrow & 6.44 (6.22 to 7.96$)$ & 9.03 (6.53 to 9.43$)$ & ns \\
\hline Tumor & 10.59 (9.66 to 11.95$)$ & $4.68(4.42$ to 5.30$)$ & 0.002 \\
\hline
\end{tabular}

5 Data is presented as median \% ID/g values with interquartile range. $P$-values $<0.05$ from 6 the Mann-Whitney U-test are shown. $L N=$ lymph node, $n s=$ non-significant. 